\title{
Plasmodium chabaudi limits early Nippostrongylus brasiliensis-induced pulmonary immune activation and Th2 polarization in co-infected
} mice

\author{
Marieke A Hoeve ${ }^{\dagger 1}$, Katie J Mylonas ${ }^{\dagger 1}$, Karen J Fairlie-Clarke ${ }^{1}$, \\ Simmi M Mahajan ${ }^{1}$, Judith E Allen ${ }^{1}$ and Andrea L Graham*1,2
}

\begin{abstract}
Address: ${ }^{1}$ Institute of Immunology and Infection Research, School of Biological Sciences, University of Edinburgh, Edinburgh, EH9 3JT, UK and ${ }^{2}$ Department of Ecology \& Evolutionary Biology, Princeton University, Princeton, New Jersey, 08544, USA

Email: Marieke A Hoeve - m.hoeve@ed.ac.uk; Katie J Mylonas - kmylonas@staffmail.ed.ac.uk; Karen J Fairlie-Clarke - Karen.FairlieClarke@ed.ac.uk; Simmi M Mahajan - smahajan@ed.ac.uk; Judith E Allen - j.allen@ed.ac.uk; Andrea L Graham* - algraham@princeton.edu

* Corresponding author †Equal contributors
\end{abstract}

Published: I December 2009

BMC Immunology 2009, 10:60 doi:10.1 186/147| I-2 I72-10-60
Received: 8 May 2009

Accepted: I December 2009

This article is available from: http://www.biomedcentral.com/l47/-2/72/10/60

(C) 2009 Hoeve et al; licensee BioMed Central Ltd.

This is an Open Access article distributed under the terms of the Creative Commons Attribution License (http://creativecommons.org/licenses/by/2.0), which permits unrestricted use, distribution, and reproduction in any medium, provided the original work is properly cited.

\begin{abstract}
Background: Larvae of several common species of parasitic nematodes obligately migrate through, and often damage, host lungs. The larvae induce strong pulmonary Type 2 immune responses, including T-helper (Th) 2 cells as well as alternatively activated macrophages (AAM $\phi)$ and associated chitinase and Fizz/resistin family members (ChaFFs), which are thought to promote tissue repair processes. Given the prevalence of systemic or lung-resident Type I-inducing pathogens in geographical areas in which nematodes are endemic, we wished to investigate the impact of concurrent Type I responses on the development of these Type 2 responses to nematode larval migration. We therefore infected BALB/c mice with the nematode Nippostrongylus brasiliensis, in the presence or absence of Plasmodium chabaudi chabaudi malaria parasites. Coinfected animals received both infections on the same day, and disease was assessed daily before immunological measurements were taken at 3, 5, 7 or 20 days post-infection.
\end{abstract}

Results: We observed that the nematodes themselves caused transient loss of body mass and red blood cell density, but co-infection then slightly ameliorated the severity of malarial anaemia. We also tracked the development of immune responses in the lung and thoracic lymph node. By the time of onset of the adaptive immune response around 7 days post-infection, malaria co-infection had reduced pulmonary expression of ChaFFs. Assessment of the $T$ cell response demonstrated that the Th2 response to the nematode was also significantly impaired by malaria co-infection.

Conclusion: P. c. chabaudi co-infection altered both local and lymph node Type 2 immune activation due to migration of $N$. brasiliensis larvae. Given recent work from other laboratories showing that $\mathrm{N}$. brasiliensis-induced ChaFFs correlate to the extent of long-term lung damage, our results raise the possibility that co-infection with malaria might alter pulmonary repair processes following nematode migration. Further experimentation in the co-infection model developed here will reveal the longer-term consequences of the presence of both malaria and helminths in the lung. 


\section{Background}

Many prevalent species of parasitic nematodes - such as Ascaris lumbricoides, which infects over a billion people [1], or Necator americanus, the most geographically widespread of the human hookworms [2] - migrate through host lungs as larvae. Lung tissue is ruptured as the larvae burst out of the blood vessels to enter the alveolar spaces. Although this process is typically asymptomatic in humans, it can also be associated with acute respiratory distress or longer term complications [3]. For example, infection with lung-migrating helminths has been associated with bronchial hyper-reactivity and other asthma symptoms among children in China [4] and Brazil [5].

The rodent parasite Nippostrongylus brasiliensis $(\mathrm{Nb})$ has proven a valuable laboratory model for nematode migration through the host body. In mice, L3 larvae injected into the skin migrate via the lungs to the small intestine, where the parasites develop into adults [6]. Peak abundance of $\mathrm{Nb}$ larvae in the lung occurs around 2 days postinfection (pi) in many strains of mice [7]. The lung migratory stage of $\mathrm{Nb}$ is associated with a strong local Type 2 inflammatory response that includes T-helper (Th)2 cells, eosinophils and basophils [8,9]. Alternatively-activated macrophages (AAM $\phi)$ have also been identified as a major component of the pulmonary response to $\mathrm{Nb}$ infection $[10,11]$. AAM $\phi$ are characterised by IL-4/IL-13-dependent production of chitinase and Fizz/resistin family members (ChaFFs) including RELM $\alpha$ (also known as Fizz1), the chitinase-like protein Ym1, and Arginase-1 [12-15], and all three proteins are consistently observed in the $\mathrm{Nb}$ infected lung $[10,11,16-18]$. Arginase- 1 is the counter-regulatory enzyme to iNOS and can thus act to suppress NO production and Type 1 effector function. Arginase- 1 also has well documented roles in tissue repair $[19,20]$ and has recently been implicated as an anti-nematode effector molecule [21]. The functions of RELM $\alpha$ and Ym1 are less well understood but, like Arginase-1, they have been strongly implicated in the response to injury [22-24] and have putative roles in the repair process, including extracellular matrix deposition and angiogenesis [25,26]. However, recent data have shown that RELM $\alpha$ and macrophage-derived arginase can also negatively regulate Th2 effector responses and thus limit the pathology associated with overzealous repair [27-29].

Although not formally proven, the association of Arginase-1, RELM $\alpha$, and Ym1 with the tissue repair process suggests that in the context of nematode infection, ChaFFs, potentially produced by AAM $\phi$, may be required to orchestrate the repair of damage caused by larval migration in order to restore lung integrity. Two recent papers have highlighted the potential for $\mathrm{Nb}$ migration to damage the lung with potentially long term consequences
$[16,18]$. Both studies document haemorrhaging of lung tissue and sustained increases in airway hyper-responsiveness. A striking novel observation in these studies is that $\mathrm{Nb}$ causes disruption of the alveolar architecture that is consistent with pulmonary emphysema many weeks after infection. Dysregulated, AAM $\phi$-mediated repair of the damage caused by the nematodes may be responsible for such detrimental outcomes [16].

Helminths with lung migratory stages are often coendemic with Type 1-inducing parasites such as malaria [30-32]. Given the potential for cross-regulation between Type 1 and Type 2 immune responses, we wished to use mouse models to investigate the consequences of coinfection for the pulmonary Type 2 immune responses induced by nematode migration. We chose to focus on $\mathrm{Nb}$ and a rodent malaria, Plasmodium chabaudi chabaudi (Pcc), that induces a potent Type 1 immune response and nonlethal infection [33]. We challenged hosts simultaneously with these two acute infections, thus demanding polarized, conflicting immune responses at the same point in time. In addition, we expected $\mathrm{Nb}$-Pcc co-infection to induce conflicting responses in the same anatomical location, because malaria-infected red blood cells (RBCs) of many species, including Pcc, adhere to endothelial cells of the microvasculature of the lung [34-36]. Furthermore, malaria itself has been shown to cause lung injury $[37,38]$. Thus, we expected the lung and draining (thoracic) lymph nodes to be potential sites of strong interactions between $\mathrm{Nb}$ and Pcc. The idea that helminth-malaria co-infection may impose Type 1-Type 2 immunological conflict is not new [30], nor is the idea that parasitic co-infection may alter the severity of pulmonary disease $[39,40]$, but our emphasis on the consequences of malaria for pulmonary Type 2 responses has not previously been explored.

Using these model systems, we assessed production of the ChaFFs, RELM $\alpha$ and Ym 1 as primary read-outs of the Type 2 effector response in the lung. We also examined thoracic lymph node (TLN) cytokine profiles, parasitology and systemic pathology, to set the co-infected lung in its wholeorganism context. By 7 days pi, malaria infection had significantly reduced the expression of ChaFFs in the lungs of co-infected animals relative to those with $\mathrm{Nb}$ only. This reduction correlated with changes in Th2 cytokines in the TLN, with co-infected mice producing significantly less IL13 , IL-10 and IL-5 than mice infected with $\mathrm{Nb}$ only. Pcc COinfection thus reduced the extent of pulmonary Type 2 activation and Th2 polarisation in response to $\mathrm{Nb}$. Future long-term experiments (up to a year in duration [16]) in the co-infection model established here will explore how helminth migration may interact with malaria infection to affect chronic lung pathology. 


\section{Results \\ $\mathrm{Nb}$ infection caused loss of both body mass and RBC density but ameliorated Pcc infection}

To investigate pulmonary immune polarization during acute helminth-malaria co-infection, on day 0 we infected female BALB/C mice with $200 \mathrm{Nb}$ L3 larvae, in the presence or absence of co-infection with $10^{5}$ Pcc-infected RBCs. Our first goal in developing this model was to characterise the systemic pathology induced by each infection and co-infection. We thus measured body mass (to the nearest $0.1 \mathrm{~g}$ ), RBC density (billions/mL), and malaria blood parasitaemia daily. We also assessed the presence of malaria parasites in lung tissue of mice culled at 3 or 7 days pi.

Consistent with previous reports in rats [41], we found that $\mathrm{Nb}$ infection induced loss of body mass in mice during the first week of infection: $\mathrm{Nb}$-infected mice reached a significantly lower minimum body mass than mice without $\mathrm{Nb}$ (Fig. 1A; $\mathrm{F}_{1,110}=21.1 ; P<0.0001$ ). This amounted to a mean loss of $0.7 \mathrm{~g}$, or $\sim 3 \%$ of body mass, and was observed regardless of malaria co-infection. No further changes in body mass among groups achieved statistical significance, though Pcc-infected mice showed an expected dip in weight around day 10 that was unaltered by $N b$.

In addition to weight loss, $\mathrm{Nb}$ infection caused $\mathrm{RBC}$ densities to be reduced by $\sim 5 \%$ (Fig. $1 \mathrm{~B}$; effect of $\mathrm{Nb}$ on minimum RBC density to 7 days pi: $\mathrm{F}_{1,110}=8.8 ; P=0.0037$ ). Unsurprisingly [33], Pcc also caused loss of RBCs by 7 days pi $\left(\mathrm{F}_{1,110}=40.2 ; P<0.0001\right)$. Between days 7 and 20 pi, $\mathrm{Nb}$-induced RBC loss resolved, but $\mathrm{Pcc}$ induced further loss of RBCs - up to $60 \%$ of original density (Fig. 1B; $\mathrm{F}_{1,110}$ $=385.4 ; P<0.0001)$. However, this was slightly ( 5\%) but significantly ameliorated by $\mathrm{Nb}$ co-infection (Fig. 1B; $\left.\mathrm{t}_{110}=4.2 ; P=0.0003\right)$.

Consistent with this slight protective effect of $\mathrm{Nb}$ on $\mathrm{RBC}$ loss during peak Pcc infection, $\mathrm{Nb}$ co-infection was associated with a modest reduction in Pcc blood parasitaemia, as determined by microscopic examination of blood films (Fig. 2A; maximum parasitaemia $\mathrm{F}_{1,62}=4.13 ; P=0.0465$ ).

By real-time PCR, the number of Pcc genome copies per $75 \mathrm{mg}$ lung homogenate sample was assessed in Pccinfected versus co-infected mice. Malaria parasites were present in the lung of most animals examined at 3 days pi and all animals at 7 days pi (Fig. 2B). At 3 days pi, which is shortly after $\mathrm{Nb}$ parasites have migrated through the lung [7] and coincident with the loss of body mass in $\mathrm{Nb}$ infected mice (Fig. 1A), co-infected mice had more Pcc genome copies per lung sample (Fig. $2 \mathrm{~B} ; P=0.010$ ). This could be due to enhanced Pcc adherence to the lung endothelia [34] during $N b$ co-infection. However, by gross examination we observed substantial haemorrhaging in all $\mathrm{Nb}$-infected mice at this time point and thus it is also possible that leakage of blood into the lung tissue increased the number of Pcc parasites in day 3 samples. At 7 days pi there was no significant difference between the $P c c$ and the $\mathrm{Nb}+\mathrm{Pcc}$ groups.

Gut nematode burden at 3 days pi varied between experiments: for example, $\mathrm{Nb}+\mathrm{Pcc}$ and $\mathrm{Nb}$ mice bore $56+10$ and $35+9$ adult nematodes, respectively, in experiment one, versus $6+4$ and $1+1$ nematodes in experiment two. Such variation has been previously reported [7] and in the present study is likely to be due to the very rapid infection kinetics typically observed for our $\mathrm{Nb}$ strain, which is not mouse-adapted (e.g., no nematodes remain in the gut at 5 days pi). A difference of a few hours in $\mathrm{Nb}$ injection times on day 0 and/or in gut sampling times on day 3 could therefore lead to the differences in nematode burden that we observed. Indeed, two lines of evidence suggest that the number of $\mathrm{Nb}$ larvae moving through the lung was much more consistent than the observed gut burdens. First, there were no significant differences among experiments in the amount of $\mathrm{Nb}$-induced weight loss (P 0.2) nor RBC loss (P 0.4). Furthermore, Type 2 immunological readouts were extremely consistent among experiments. For example, TLN production of IL-4, IL-5, and IL13 in response to $\mathrm{Nb}$ infection did not differ significantly among experiments ( $P \sim 0.9,0.8$, and 0.9, respectively). Still, in order to be certain that experimental variations were not confounding any of our conclusions, we controlled for experiment in all statistical analyses of combined data (as described in Methods).

Nb-induced ChaFFs in the lung peaked around 5-7 days pi Before we undertook studies of Type 2 immune responses in the lung during co-infection, we assessed the time course of $\mathrm{Nb}$-induced pulmonary expression of ChaFFs. Previous work has mainly focused on ChaFF mRNA expression in the lungs $[10,11,16,17]$. We wished to also ascertain protein expression in situ after $\mathrm{Nb}$ infection, to more closely determine the location of these proteins in vivo. Female BALB/c mice were infected with $200 \mathrm{Nb}$-L3s, or injected with PBS as a control, and RELM $\alpha$ and Ym1 protein levels were determined in BALF (via Western blots) and lungs (via IHC) at days 3, 5, 7, 15, 20 and 26 pi, to reflect the early events, peak Th2 time point and resolution stages of $\mathrm{Nb}$ infection [9].

RELM $\alpha$ and $Y m 1$ were both detected in BALF at 3 days pi, and rose to a peak around 5-7 days pi (Fig. 3A, B). Expression of both proteins dropped off by days 20-26 pi. Histological analysis of Ym1-stained lung sections from infected mice illustrated this peak, with an increase in the intensity and area of anti-Ym 1 staining at 5-7 days pi (Fig. $3 \mathrm{E}, \mathrm{F})$. These representative micrographs also show the 


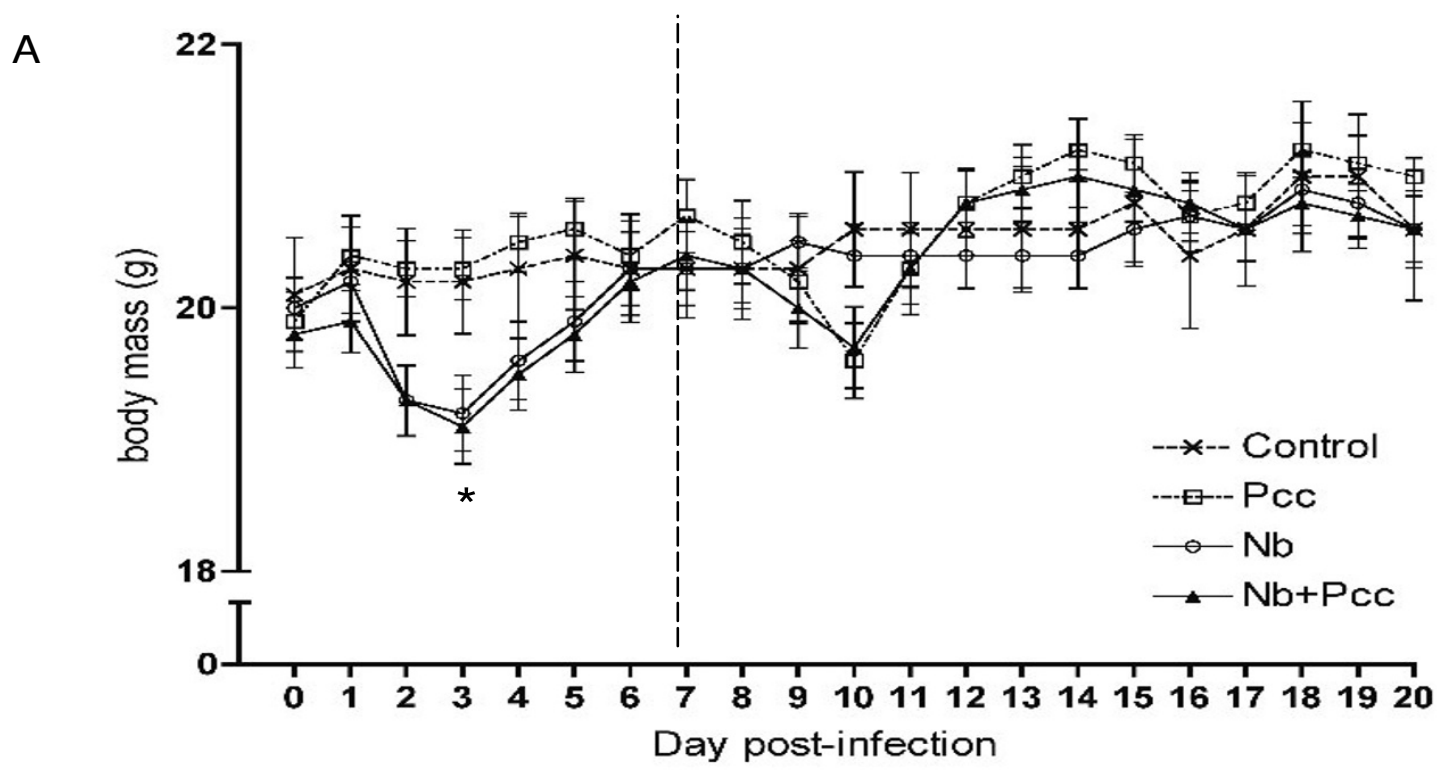

B

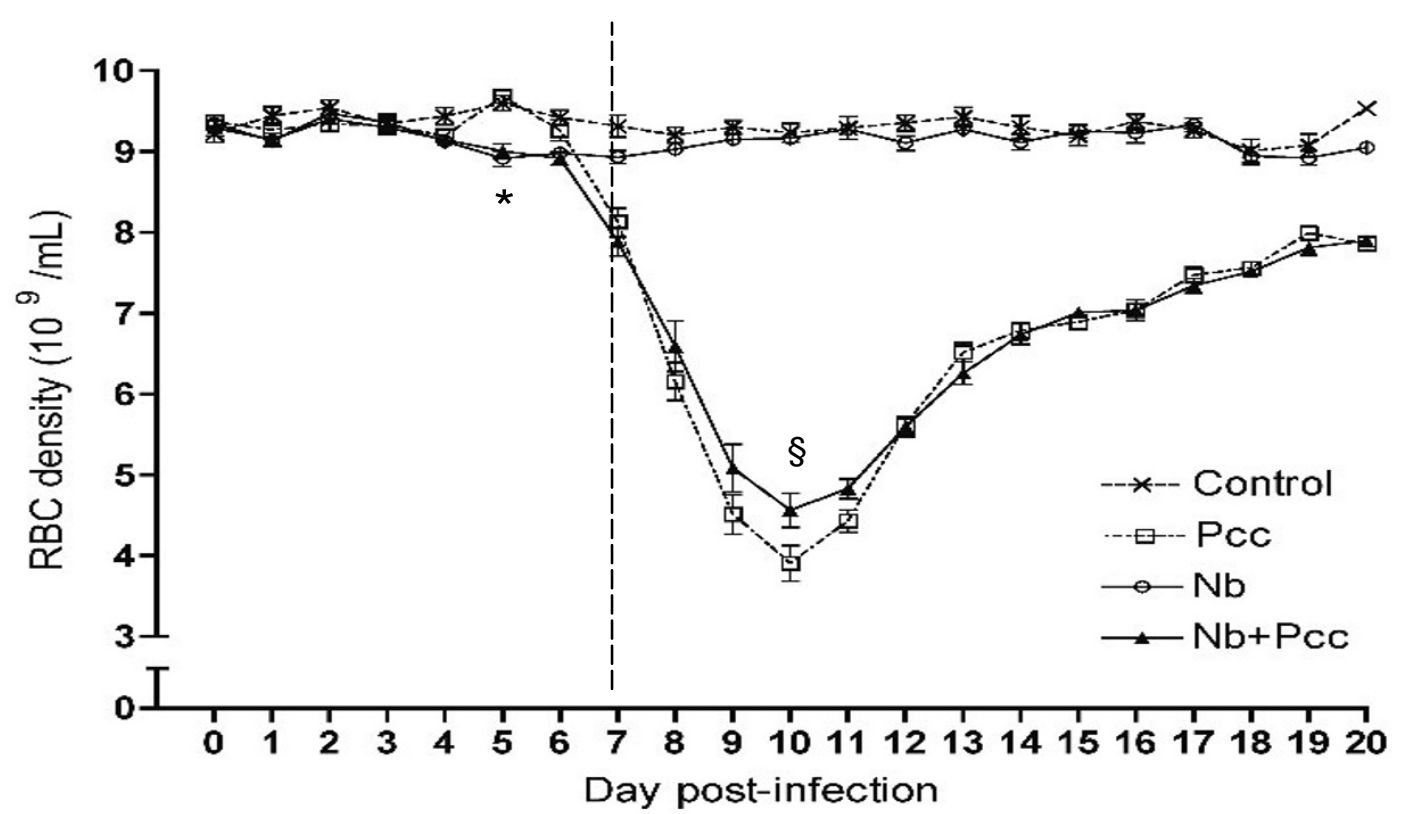

Figure I

Pathology, measured as loss of body mass (A) and red blood cell density (B). Mice were infected with $200 \mathrm{Nb} L 3$ larvae and/or $10^{5}$ Pcc-infected RBCs on day 0 , then weighed daily to the nearest $0.1 \mathrm{~g}$. Daily samples of blood were taken for flow cytometric analysis of RBC density. (A) Nb infection induced significant loss of body mass during the first week of infection (lower minimum body mass than mice without $\mathrm{Nb} ; \mathrm{P}<0.000 \mathrm{I}$ ). (B) $\mathrm{Nb}$ also induced significant loss of RBCs that week (lower minimum RBC density to 7 days pi than mice without $N b ; P=0.0037)$, whereas $P c c-i n d u c e d ~ R B C$ loss was mainly apparent during the second week of infection (lower minimum RBC density to 20 days pi than mice without $P c c ; P<0.000 I$ ). Nb co-infection significantly ameliorated this (higher minimum RBC density in co-infected compared to Pcc-infected mice; $P=0.0003$ ). Means \pm SEM from combined results of 3 independent experiments (each with 4-9 mice per group per time point) are shown. The vertical dashed line indicates the two time periods for which minimum weight and RBC density were analysed: up to 7 days pi, and 7-20 days pi, as described in Methods. The symbol * indicates statistical significance of the $\mathrm{Nb}$ main effect, and $\S$ indicates significance of the difference between co-infected and Pcc mice. 
influx of Ym1-positive inflammatory cells into the lung tissue that was evident by day 7 - e.g., alveolar and peribronchial inflammation. Of note, although infiltrating cells were $\mathrm{RELM}^{+}$(data not shown) and $\mathrm{Ym}^{+}{ }^{+}$, epithelial cells also appeared to be a major source of these molecules. Reece et al. (2006) clearly demonstrate macrophages as sources of these proteins in the lung during $\mathrm{Nb}$ infection but do not mention epithelial cells [11]. Our data are more consistent with a recent study in which RELM $\alpha$ was localized primarily to epithelial cells in $\mathrm{Nb}$ infected mice [29]. Further, several reports on inflamed allergic (asthma model) and fibrotic (bleomycin- or gammaherpes virus-induced) rodent lungs, as well as our own unpublished data, demonstrate expression of both Ym1 and RELM $\alpha$ by epithelial cells $[26,42,43]$. By 15-26 days pi (Fig. 3G, H, I), Ym1 protein expression had returned to near-background (Fig. 3C), with reduced inflammatory influx and resolution of the thickened and disrupted epithelial layer that was apparent at earlier time points. These data are supportive of the idea that pulmonary activation of AAM $\phi$ is a highly dynamic process [44].

\section{Pcc changed the dynamics of expression of $\mathbf{N b}$-induced ChaFfs, especially 7 days pi}

To assess the effect of Pcc co-infection on the dynamics of $N b$-induced pulmonary AAM $\phi$ and Type 2 epithelial cell activation, we next analysed both mRNA and protein expression of two ChaFFs, RELM $\alpha$ and Ym1, at a series of time points during co-infection. We also measured local mRNA expression of iNOS as a marker for Type 1 macrophage activation [19], which might be expected during malaria [45]. Furthermore, we measured mRNA of Type 1 cytokines (IL-12p40, TNF- $\alpha$, and IFN- $\gamma$ ), as well as mRNA of IL-13, a key cytokine likely to drive production of Type 2 effector molecules such as the ChaFFs [12-15]. We chose to examine the effect of malaria infection around the peak of larvae-induced damage (i.e., day 3 pi) [7] and the time of transition to adaptive Type 2 responses (i.e., days 5-7 pi) $[9,11]$. We also assessed a later time point well into the adaptive immune phase: 20 days pi.

Analysis of ChaFF mRNA expression at 3, 5, 7 and 20 days pi suggested that the strongest interactions between $\mathrm{Nb}$ and $P c c$-induced responses in lung tissue occurred 5-7 days pi (Fig. 4A, B). Indeed, because days 5-7 pi represented a time of strong ChaFF expression in $\mathrm{Nb}$ lung (Fig. 3) and day 7 pi coincided with the presence of Pcc there (Fig. 2B), it is perhaps unsurprising that days 5-7 pi could be the time of maximum effect of Pcc co-infection. At 3 days pi, there was a transient elevation of RELM $\alpha$ mRNA in co-infected compared to $N b$-infected mice $(P=0.0257)$ that was reversed over the next few days: differences between the groups were not significant at 5 days pi, but RELM $\alpha$ gene expression was significantly reduced in coinfected mice at 7 days pi (Fig. $4 \mathrm{~A} ; \mathrm{F}_{1,25}=7.5, P=0.0113$, for combined analysis of experiments). Expression of Ym1 mRNA was also significantly lower in co-infected than $\mathrm{Nb}$ mice at days 5 and 7 pi (Fig. 4B: day $5 P=0.0442$; day $7 \mathrm{~F}_{1,25}=9.5, P=0.005$, for combined analysis of experiments). In agreement with these observations, day 7 expression of Arginase-1 mRNA was significantly lower in the lungs of co-infected mice than in mice that had $\mathrm{Nb}$ only (data not shown; $F_{1,24}=7.7, P=0.0104$ ). Furthermore, ChaFF expression is known to be driven by engagement of IL-4R $\alpha$ [24] by IL-4 and/or IL-13; accordingly, IL13 mRNA expression in the lungs of co-infected mice was significantly reduced compared to $\mathrm{Nb}$-infected mice at 5 days pi (Fig. 4C: $P=0.0169$ ). This suggests that suppression of IL-13 by Pcc may be responsible for the reduced ChaFFs in co-infected mice. At 20 days pi, mRNA expression for RELM $\alpha(P=0.0101)$ was slightly elevated in coinfected relative to $\mathrm{Nb}$-only mice, but ChaFF and IL-13 mRNA expression had otherwise largely returned to background levels. Throughout this time course, Pcc-infected and uninfected animals expressed little or no mRNA for the ChaFFs.

In support of the mRNA data, when we analysed protein expression in lung BALF using Western blotting, we saw a significant day 7 pi reduction of both RELM $\alpha$ (Fig. 5A; $\mathrm{F}_{1,25}=8.7, P=0.0067$, for analysis of combined experiments) and Ym1 (Fig. 5B; $F_{1,25}=7.7, P=0.0104$, for analysis of combined experiments) in co-infected mice compared to $\mathrm{Nb}$-infected mice. By day $20 \mathrm{pi}$, the pattern had reversed, with co-infected mice expressing more $\operatorname{RELM} \alpha(P=0.0398)$ and $\mathrm{Ym} 1(P=0.0171)$ than $N b$ mice. ChaFF expression in Pcc-infected mice did not differ from near-null expression in uninfected control mice (Fig. 5A, B). Importantly, BAL cell counts and cellular composition did not differ significantly among groups at any timepoint. There was a non-significant elevation in total numbers of cells in co-infected mice at 3 days pi and in $\mathrm{Nb}$ mice at 5 days pi, which might partly explain the elevation in ChaFFs at these early timepoints. However, any apparent differences were entirely absent from the 7 and 20 day BAL samples. Therefore, the observed effects on ChaFF protein expression are unlikely to be due to differences in cellular makeup alone, particularly at 7 and 20 days pi. Further, the inflammatory cells may not be the major source of CHaFF proteins in lavage fluid. The pattern and intensity of epithelial cell staining (see Fig 6C) suggests that these cells may be largely responsible for the changes in $\mathrm{mRNA}$ and BALF protein.

IHC scoring of lung sections further confirmed these dynamics. At both day 5 pi and day 7 pi, the intensity of RELM $\alpha$ (Fig 6A) and Ym1 (Fig 6B) staining in the lungs of co-infected animals was reduced compared to $\mathrm{Nb}$ mice, though the RELM $\alpha$ difference did not achieve statistical significance at day 7 (day 5: RELM $\alpha=0.0056$; Ym1 $P=$ 


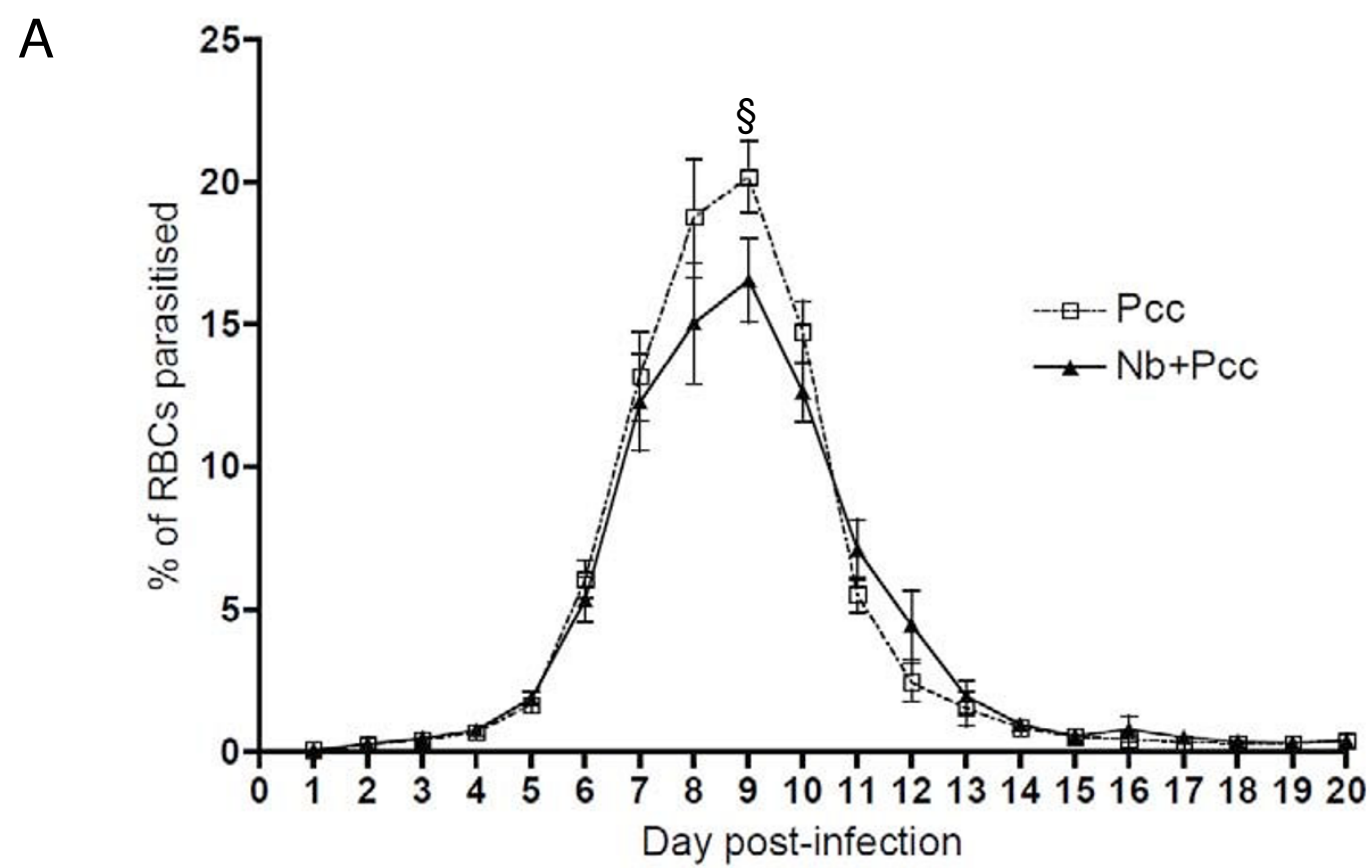

B

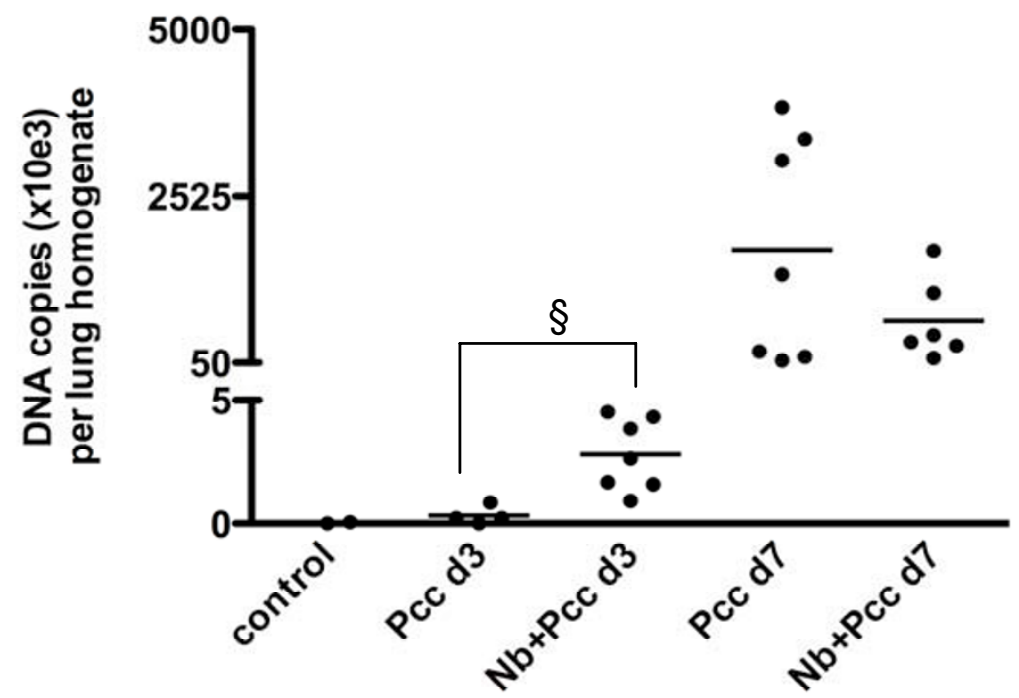

Figure 2

Malaria parasites in the blood (A) and lungs (B) of Pcc-infected and co-infected mice. (A) Co-infected mice $(N b+P c c)$ had a lower peak proportion of parasitized RBCs than Pcc-infected mice did $(P=0.0465)$, as determined by $1000 \times$ microscopic examination of Giemsa-stained thin blood films. Means \pm SEM from combined results of 3 independent experiments (each with 4-9 mice per group per time point) are shown. (B) Co-infected mice harboured greater numbers of Pcc genome copies per lung sample than Pcc mice at 3 days pi $(P=0.01)$, as assessed by real-time PCR of lung homogenates (derived from $75 \mathrm{mg}$ lung) using MSP-I specific primers. Genome copies were apparent in both Pcc infected groups at 7 days pi and the copy numbers no longer differed significantly between groups. This experiment included 4-7 mice per group. The symbol $\S$ indicates significance of the difference between co-infected and Pcc mice. 
A
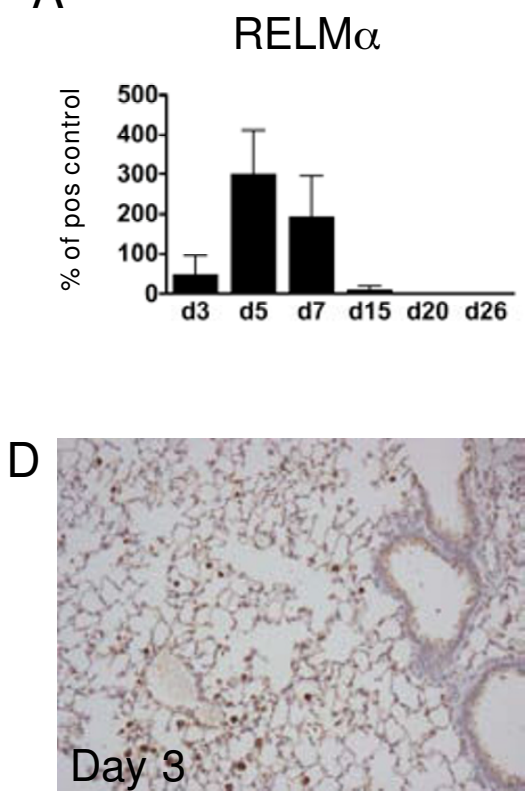

$\mathrm{G}$

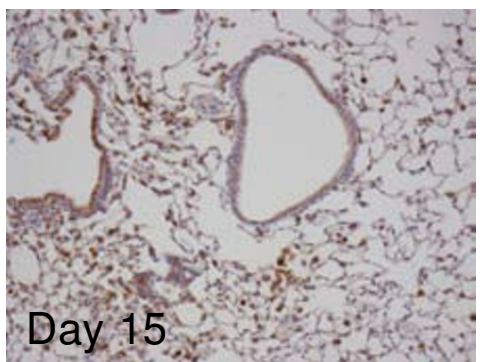

B

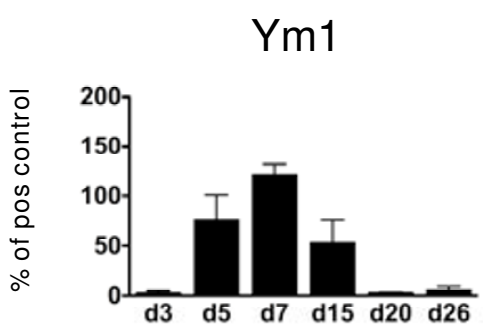

Alveolar macrophages

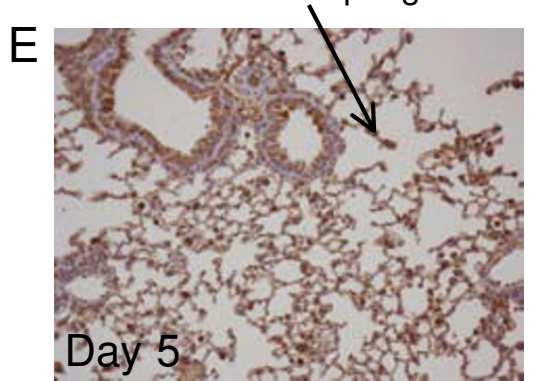

$H$

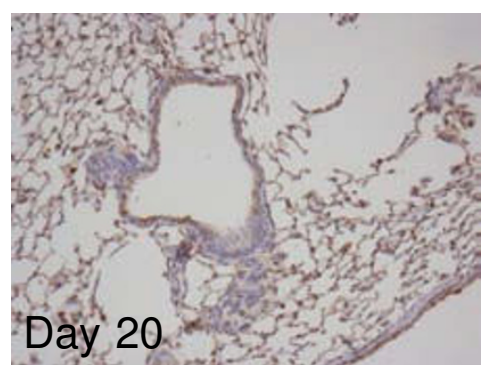

C
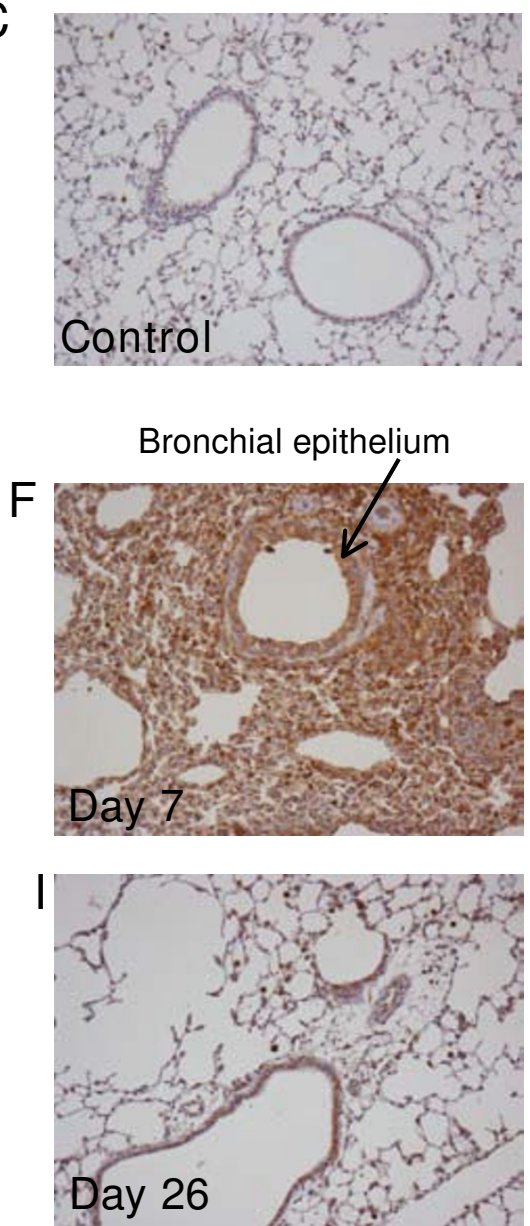

Figure 3

Time course of protein expression of ChaFFs in $\mathbf{N b}$ infected lungs. Western blot analysis of lung lavages harvested at different time points post $\mathrm{Nb}$ infection (4 Nb mice per timepoint) suggested that the secretion of ChaFFs RELM $\alpha$ (A) and Ym I (B) peaked around 5-7 days post infection. Data are expressed as percentage of a positive control sample (pooled lung lavages of three $\mathrm{Nb}$-infected mice). Representative photomicrographs from $\mathrm{Nb}$-infected lung tissue sections stained histologically for $\mathrm{Yml}$ at the indicated time points, plus an uninfected control lung (C), illustrate peak expression of brown $\mathrm{Yml}$ staining of epithelial cells and macrophages (E-F).

0.0153; day 7: RELM $\alpha=0.1011 ;$ Ym1 $P=0.0171)$. Representative micrographs from day 7 pi show the reduced intensity of RELM $\alpha$ staining in co-infected animals relative to $\mathrm{Nb}$ mice and no RELM $\alpha$ staining in Pcc mice (Fig. $6 \mathrm{C}$ ). No differences among groups were detected by IHC at days 3 or 20 pi. Therefore, the expression pattern of ChaFF protein in situ was largely in agreement with mRNA in whole lung tissue (Fig. 4) and protein expression in the BALF (Fig. 5). As discussed above for the time course of $\mathrm{Nb}$ infection (Fig. 3), although $\mathrm{Ym}^{+}$and RELM $\alpha^{+}$macrophages were present in lung IHC sections, the predominant cell type expressing these molecules appeared to be epithelial cells. Furthermore, lung macrophages in this system do not appear to become classically activated, as assessed by lung mRNA for iNOS and IL-12p40, which were not detectable in any mice at any time point, and TNF- $\alpha$, which was detectable but at low levels that did not differ among groups (data not shown). However, IFN $\gamma$ was elevated in the lung tissue of all Pcc infected mice, regardless of $\mathrm{Nb}$ co-infection, at day $7 \mathrm{pi}$ (Fig. 7).

\section{Cytokine production in local LN largely mirrored pulmonary ChaFF expression}

To assess whether pulmonary ChaFF patterns corresponded to immune responses in the draining thoracic lymph node (TLN), we performed in vitro culture of TLN 
A

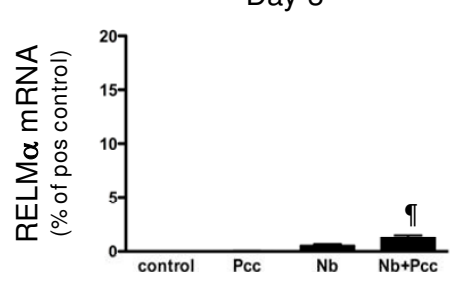

B

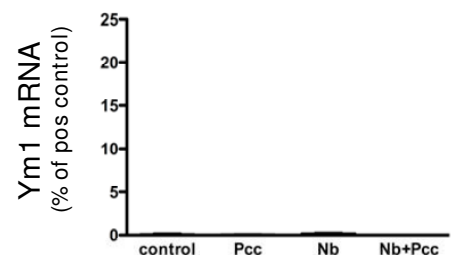

C

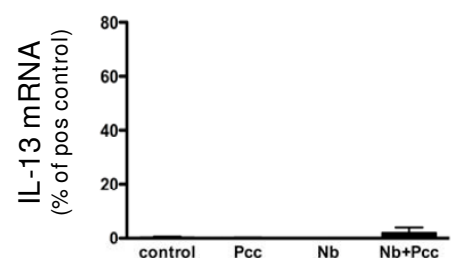

Day 5
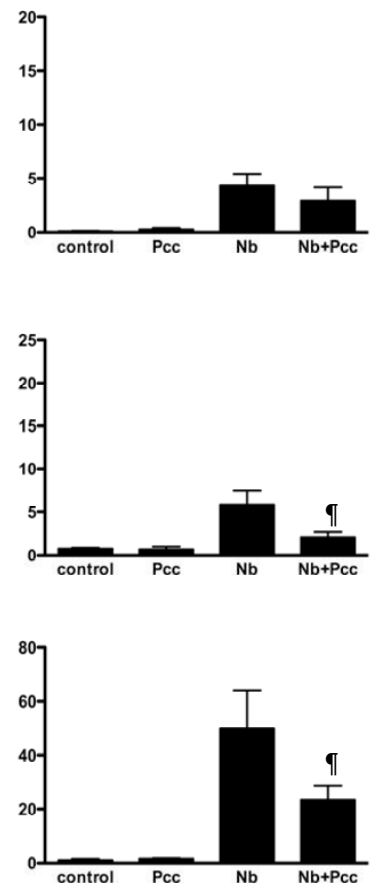

Day 7
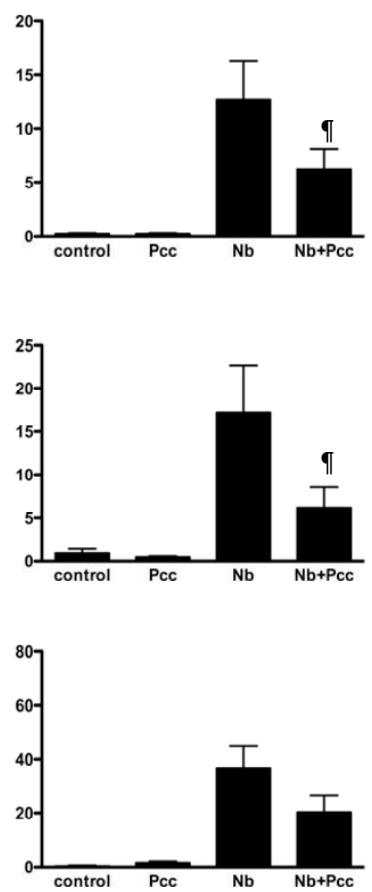

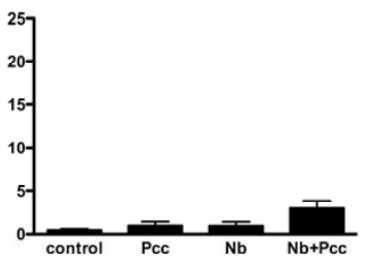

Day 20
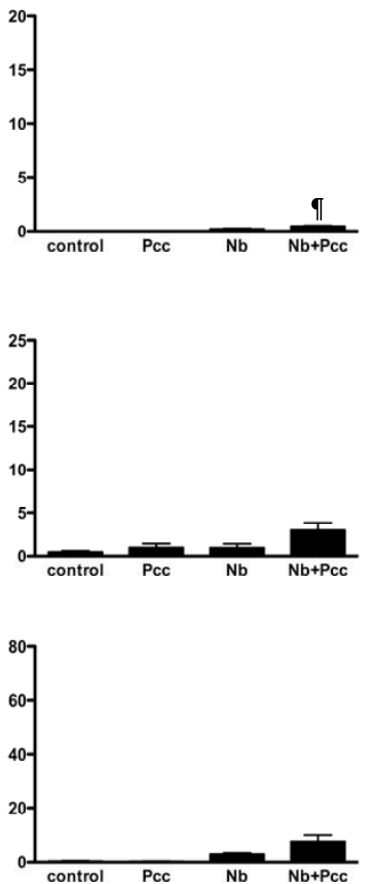

\section{Figure 4}

ChaFF and IL- 13 mRNA expression in the lungs of $\mathbf{N b}$, Pcc and co-infected mice. Real-time RT-PCR of mRNA from lung tissue harvested at 3, 5, 7 or 20 days pi showed that the effect of Pcc on $N b$-induced expression of RELM $\alpha(A)$ and $Y m I$ (B) changed over time. RELM $\alpha$ was transiently elevated in co-infected $(N b+P c c)$ compared to $N b$ mice at 3 days pi $(P=0.0257)$, but expression of mRNA for RELM $\alpha(A)$, and $\mathrm{YmI}(\mathrm{B})$ was then found to be significantly lower in the lungs of $N b+P c c$ mice than in $\mathrm{Nb}$ mice by 7 days pi (RELM $\alpha, P=0.01 \mathrm{I}$; $\mathrm{YmI}, P=0.005$ ). IL-I3 mRNA expression (C) largely mirrored this pattern, as it was significantly reduced in $N b+P c c$ mice compared to $N b$ mice at 5 days pi $(P=0.0169)$. At 20 days pi, however, RELM $\alpha$ (A) was again significantly elevated in $\mathrm{Nb}+\mathrm{Pcc}$ relative to $\mathrm{Nb}$ mice. $(P=0.0 \mathrm{I})$ Data are expressed as percentage of positive control samples (for RELM $\alpha$ and $\mathrm{YmI}$, peritoneal macrophages of a mouse implanted with Brugia malayi adult parasites for 3 weeks [72]; for IL-I3, spleen of an MHV-68 infected IFN $\gamma R-K O$ mouse [63]). Bars indicate mean \pm SEM of 2 combined independent experiments, each with 4-9 mice per group per timepoint. The symbol $\mathbb{T}$ indicates significance of the difference between coinfected and $\mathrm{Nb}$ mice ( $P$ values included above and in Results text).

cells, in media alone or with antigen or ConA. At 3 and 5 days pi, there were no significant differences in supernatant cytokine concentrations among infection groups. However, by 7 days pi, differences among the groups were apparent, as outlined below. No antigen-specific responses were observed (i.e., no cytokines in excess of spontaneous secretion in media alone) until 20 days pi (discussed below). Spontaneous and ConA-induced cytokines exhibited identical patterns, though spontaneous responses were of lower magnitude.

At 7 days pi, $\mathrm{Nb}$ infection in singly as well as co-infected mice was associated with significantly elevated ConAinduced production of IL-4, IL-13, IL-5, and IL-10 compared to uninfected and Pcc-infected mice (Fig. 8A, B, C, $\mathrm{D}$; all $P$ for $\mathrm{Nb}$ main effect $<0.0001)$. Of interest, IL- 6 and
sTNFR1 were also associated with $\mathrm{Nb}$ but not $P c c$ infection (Fig. 8E, F; both $P$ for $N b$ main effect $<0.0001$ ). TNF- $\alpha$ production did not vary among infection groups (Fig. 8G), but $P c c$ infection was associated with significantly elevated IFN- $\gamma$ production compared to uninfected and $\mathrm{Nb}$ infected mice (Fig. 8H; $P$ for $P c c$ main effect $<0.0001$ ). To our knowledge, TLN polarization by systemic malaria infection has not been previously reported. The Th1 bias of the observed response to $P c c$ was unsurprising.

Co-infected mice differed from singly-infected mice in ConA-induced production of some of these cytokines. For example, IL-13, IL-5, and IL-10 production were significantly reduced in co-infected compared to $\mathrm{Nb}$-infected animals (Fig. 8B, C, D; $\mathrm{t}_{61}=7.3,18.8,8.1$ and $P=0.011$, $0.0001,0.007$, respectively), while IFN- $\gamma$ production was 
A

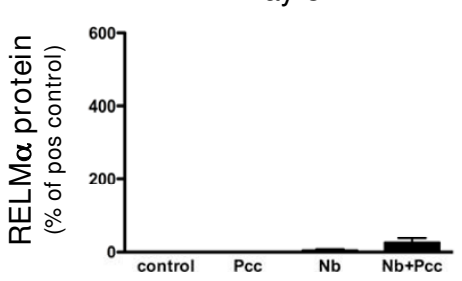

B

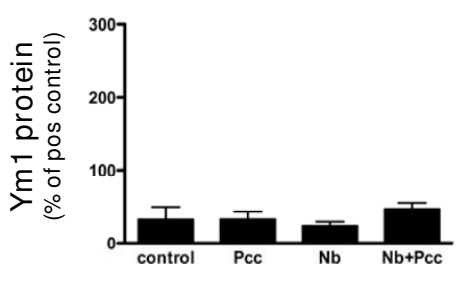

Day 5
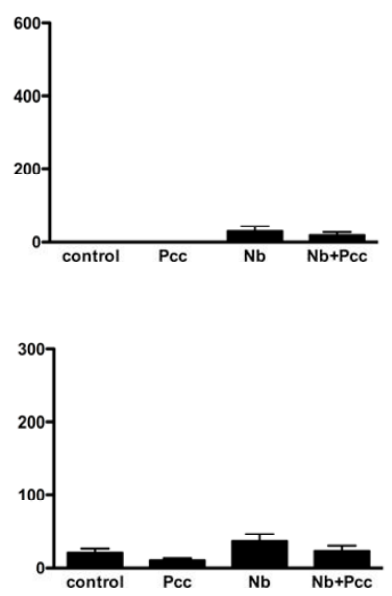

Day 7
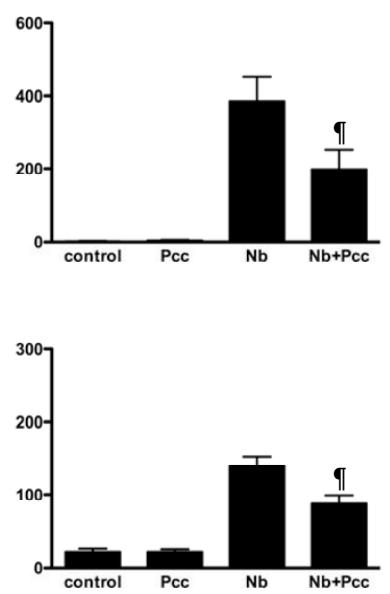

Day 20
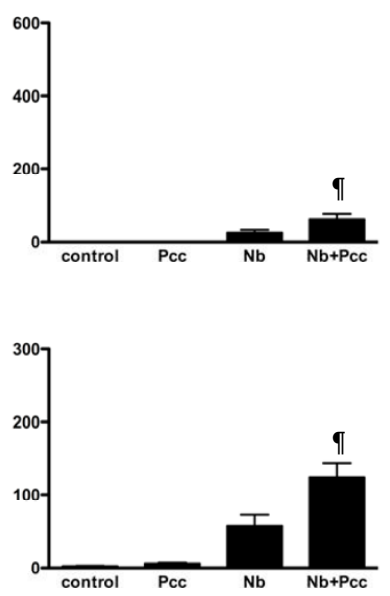

\section{Figure 5}

Western blot analysis of ChaFF protein expression in BALF of $\mathbf{N b}$, Pcc and co-infected mice. Lung lavages harvested at days 3, 5, 7 and 20 pi indicated that the ChaFF proteins RELM $\alpha(A)$ and $Y m I$ (B) exhibited temporal dynamics that were similar to those observed for mRNA expression in lung tissue (Fig. 4). In particular, expression of both proteins was significantly lower in the lungs of co-infected $(N b+P c c)$ than in $N b$ mice at 7 days pi (RELM $\alpha P=0.0067$ and $Y m I P=0.0104)$. This pattern had reversed by 20 days pi, with increased ChaFF protein expression in $N b+P c c$ compared to $N b$ mice (RELM $\alpha P=$ 0.0398 and $Y \mathrm{ml} P=0.017 \mathrm{I}$ ). Data are expressed as percentage of a positive control sample (pooled lung lavages of three $\mathrm{Nb}$ infected mice). Bars indicate mean \pm SEM of combined results of 2 independent experiments, each with 4-9 mice per group per timepoint. The symbol $\mathbb{T}$ indicates significance of the difference between co-infected and $\mathrm{Nb}$ mice $(P$ values included above and in Results text).

reduced in co-infected compared to Pcc-infected animals (Fig. $8 \mathrm{H} ; \mathrm{t}_{61}=8.4$ and $P=0.006$ ). These results provide evidence of cross-regulation between Th1 and Th2 immune responses in the local lymph node during the first week of co-infection. This finding is consistent with a wide range of studies of murine co-infection (reviewed in $[30,46])$.

By 20 days pi, the overall strength of TLN cytokine responses had waned, but antigen-specific responses were detectable. Correcting for background (spontaneous) secretion of cytokines in wells with media alone, antigenspecific responses to crude helminth $(\mathrm{Nb} \mathrm{Ag})$ and recombinant malaria (MSP- $1_{19} \mathrm{Ag}$ ) antigens were each observed for a subset of the cytokines measured (Fig. 9). For example, $\mathrm{Nb}$ infection was associated with strong $\mathrm{Nb}$ Ag-specific IL-13 responses (Fig. 9A: $P<0.0001$ ), regardless of co-infection. Co-infection, however, had a significant boosting effect on $\mathrm{Nb}$ Ag-specific IL-5 (Fig. 9B: $P=0.0025$ for the comparison with $\mathrm{Nb}$ mice; $P<0.0001$ for the comparison with $P c c$ mice). Co-infection was also associated with significantly elevated MSP-1 ${ }_{19}$ Ag-specific IL-6 (Fig. 9C: $P=0.0163$ for the comparison with $\mathrm{Nb}$ mice; $P=$ 0.0112 for the comparison with $P c c$ mice). TNF- $\alpha$ produc- tion, though greater than background, did not differ significantly among groups (Fig. 9D).

\section{Discussion}

Our primary aim in this study was to address the interplay of two acute infections that place conflicting demands on the host immune response, particularly in the lung. We wanted to focus on Type 1-Type 2 cross-regulation rather than any effects of regulatory $\mathrm{T}$ cells, so we opted for a model of acute rather than chronic helminthiasis. In addition, although anatomical compartmentalization does not preclude immunological interaction - for example, gut-restricted helminths can induce a strong systemic Th2 bias [47] - compartmentalization can buffer the effects of co-infection [48]. We thus chose murine infection models that would pose an immunological conflict in anatomical space as well as time post-infection (pi). The dynamics we were investigating may have real life corollaries, because nematode migration occurs in the lungs of over a third of the world's human population $[1,2]$, many of whom are co-infected with malaria [31,32]. However, because both of our murine models ( $\mathrm{Pcc}$ and $\mathrm{Nb}$ ) produce self-resolving infections, the effects of co-infection on anaemia and on pulmonary immunology reported here cannot be firmly 
A

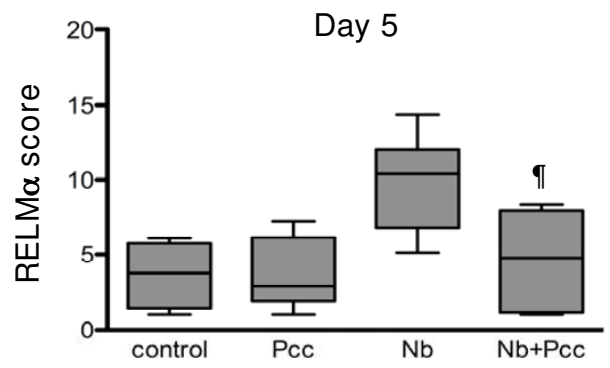

B

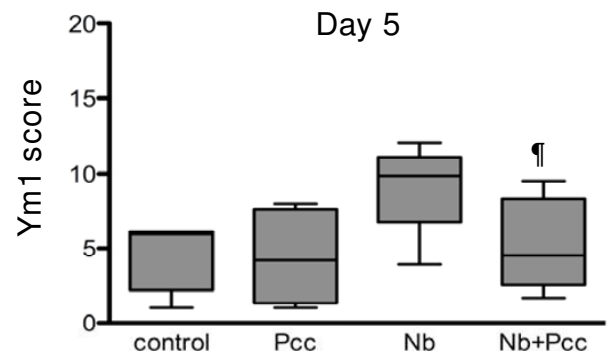

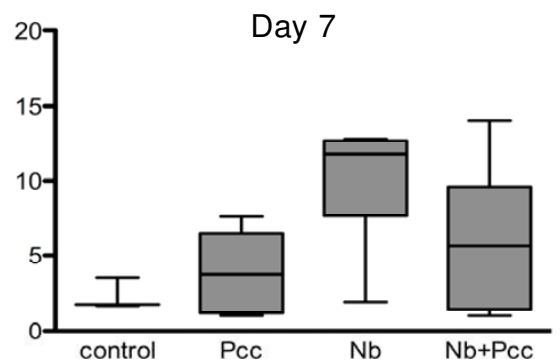

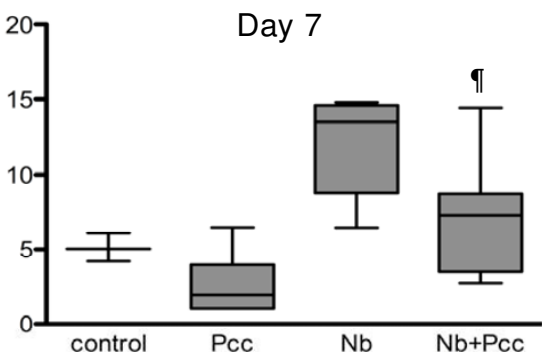

C
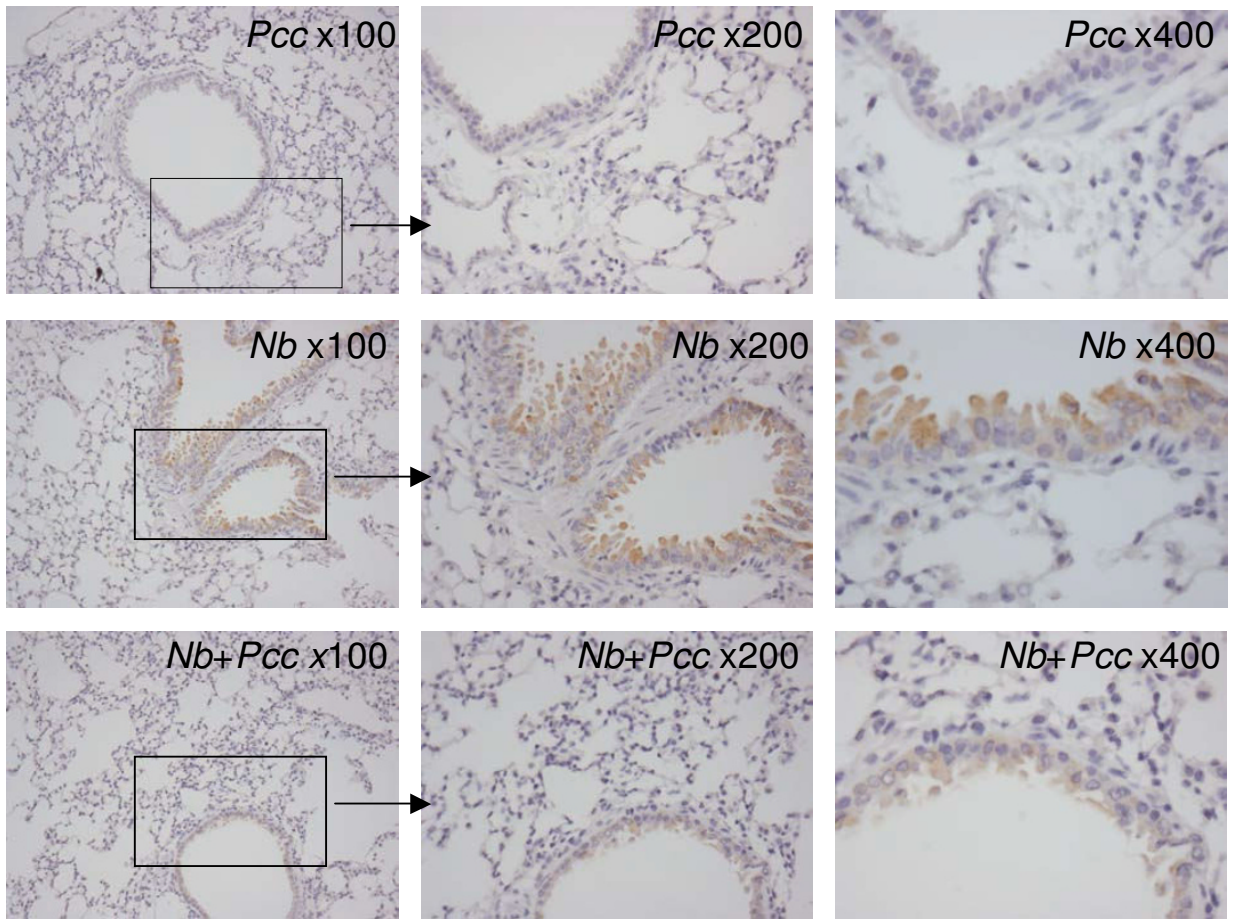

Figure 6

Immunohistochemical analysis of ChaFF protein expression in the lungs of $\mathbf{N b}$, Pcc and co-infected mice. Protein expression in lung sections corroborated BALF concentrations of ChaFF proteins observed around 7 days pi, as illustrated by days 5 and 7 pi staining intensity scores for RELM $\alpha(A)$ and $\mathrm{YmI}(\mathrm{B})$ as well as representative micrographs (at increasing magnification) of day 7 pi slides stained for RELM $\alpha$ (C). Down-regulation of ChaFFs was observed in co-infected mice $(N b+P c c)$ compared to $\mathrm{Nb}$ mice; differences were significant for both RELM $\alpha$ and $\mathrm{YmI}$ at 5 days pi (RELM $\alpha=0.0056$ and $\mathrm{YmI} P=$ $0.0153)$ and for $\mathrm{YmI}$ at 7 days pi $(P=0.017 \mathrm{I})$. Scores were obtained by analyzing bronchial epithelium in ten fields per mouse using a scoring system described in Methods. The whisker-and-box graphs with minimum and maximum values depict results from a representative experiment with 4-9 mice per group. The symbol $\mathbb{T}$ indicates significance of the difference between coinfected and $\mathrm{Nb}$ mice ( $P$ values included above and in Results text). 


\section{Day 7}

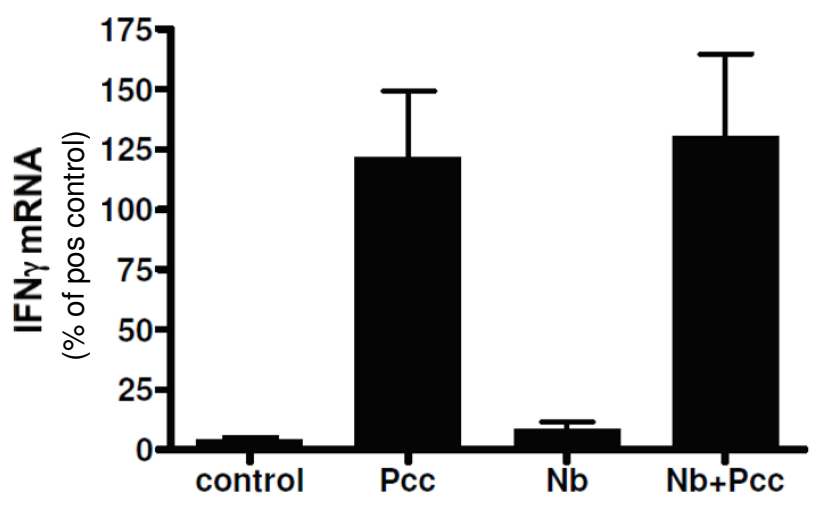

Figure 7

Lung mRNA for the Type I cytokine IFN- $\gamma$ at 7 days pi. Real-time RT-PCR of mRNA from lung tissue harvested at 3, 5, 7 or 20 days pi using primers for Type I markers iNOS, IL-I $2 p 40$, TNF- $\alpha$, and IFN- $\gamma$ were largely negative. For example, no iNOS nor IL- I 2p40 was detected in any mice, and although TNF- $\alpha$ was detected at low levels, its expression did not differ among groups of mice. At 7 days pi, however, IFN- $\gamma$ was significantly upregulated in all mice with Pcc infection, with or without $\mathrm{Nb}$ co-infection, as depicted here. Data are expressed as percentage of a positive control sample (peritoneal macrophages of a thioglycolate-injected mouse [10]). Mean \pm SEM from a representative experiment with 4-9 mice per group per timepoint are shown.

associated with chronic disease outcomes until longer term co-infection studies are performed.

We quantified the health of mice in our experiments using two measures that have proven informative during Pcc infection [49] and Pcc-nematode co-infection [50]: body mass and RBC density. To our knowledge, this is the first report demonstrating that murine $\mathrm{Nb}$ infection has a negative impact on both parameters, although reduced weight gain in young $\mathrm{Nb}$-infected mice has previously been reported [40]. $\mathrm{Nb}$ caused a statistically significant, transient 3\% loss of body mass from approximately 2-4 days pi, and in other experiments using a higher dose (500 L3s), mice lost closer to $10 \%$ of their starting body mass (unpublished data). Migration of $\mathrm{Nb}$ larvae through the lungs has previously been shown to cause two spells of inappetance and thus weight loss in rats, one associated with migration of larvae and the other with establishment of adults in the gut [41]. We detected only one period of loss of body mass; mice may be spared the second spell given the brief survival of adult $\mathrm{Nb}$ in mice, particularly for parasite strains, such as ours, that are not mouse-adapted. We also observed a transient loss of RBC density in $\mathrm{Nb}$ infected mice. It was rather surprising that this effect most likely caused by haemorrhaging of the lung follow- ing larval migration - was detectable at the systemic level. This suggests that the capillary damage and ingestion of RBCs by alveolar macrophages following lung migration of $\mathrm{Nb}[11,16]$ are associated with considerable blood loss.

A diverse range of outcomes is possible when helminths and malaria co-infect a host. Co-infected mice in our study experienced two periods of RBC loss in quick succession - first $\mathrm{Nb}$-induced and then Pcc-induced. However, they had slightly higher RBC densities than Pcc-infected mice did, at the time of most severe malarial disease. This was associated with a small reduction in malaria parasitaemia in the blood. These results contrast with several studies of helminth-malaria co-infection in mice, in which malaria parasitemia was increased [51-54], and/or malarial symptoms exacerbated, in at least some groups of co-infected mice [50-55]. For example, in contrast to the lethal inflammatory liver disease recently described in mice simultaneously co-infected with Heligmosomoides polygyrus and Pcc [55], we observed subtle amelioration of malarial disease and no deaths. This disparity in the severity of co-infection could be due to the fact that we worked with a different mouse strain (BALB/c versus Helmby's C57BL/6) as well as a different helminth species that migrates differently through the host body. However, we detected an elevation in MSP- $1_{19}$-specific IL-6 due to coinfection, so it is possible that the emergent IL-17/IL-23 axis described by Helmby [55] may likewise be involved in our co-infection system, though not in organs that negatively impact short-term survival. Indeed, the mechanisms underlying the slightly protective effect of $\mathrm{Nb}$ observed here are not yet clear. We are investigating possible immunological causes of this protection, including innate mechanisms such as IFN- $\gamma^{+}$NK cells [56] and adaptive mechanisms such as cytophilic antibody isotypes [33] that could promote malaria clearance; either might be altered by acute $\mathrm{Nb}$ co-infection. However, it is also possible that lower parasitaemia might be the consequence of the RBC density changes induced by $\mathrm{Nb}$, as previous coinfection studies have shown that helminths can limit RBC availability to malarial parasites and thereby cap their replication (e.g., [57]). Control of microparasites by Th1 immunity and by RBC limitation are not mutuallyexclusive possibilities [58] and both might be operating in our model system. Finally, it is possible that the sequestration habits of Pcc parasites [59] are altered by $N b$. These mechanisms remain to be investigated.

Our results largely resemble those reported for other $\mathrm{Nb}$ microparasite pairings. For example, during co-infection of mice with $\mathrm{Nb}$ and either Toxoplasma gondii [60] or Chlamydophila abortus [61], significantly reduced Th2 responses (compared to mice with $\mathrm{Nb}$ infection) have been observed, independent of the interval between infections $[60,61]$. These data suggest that Pcc is not the only 

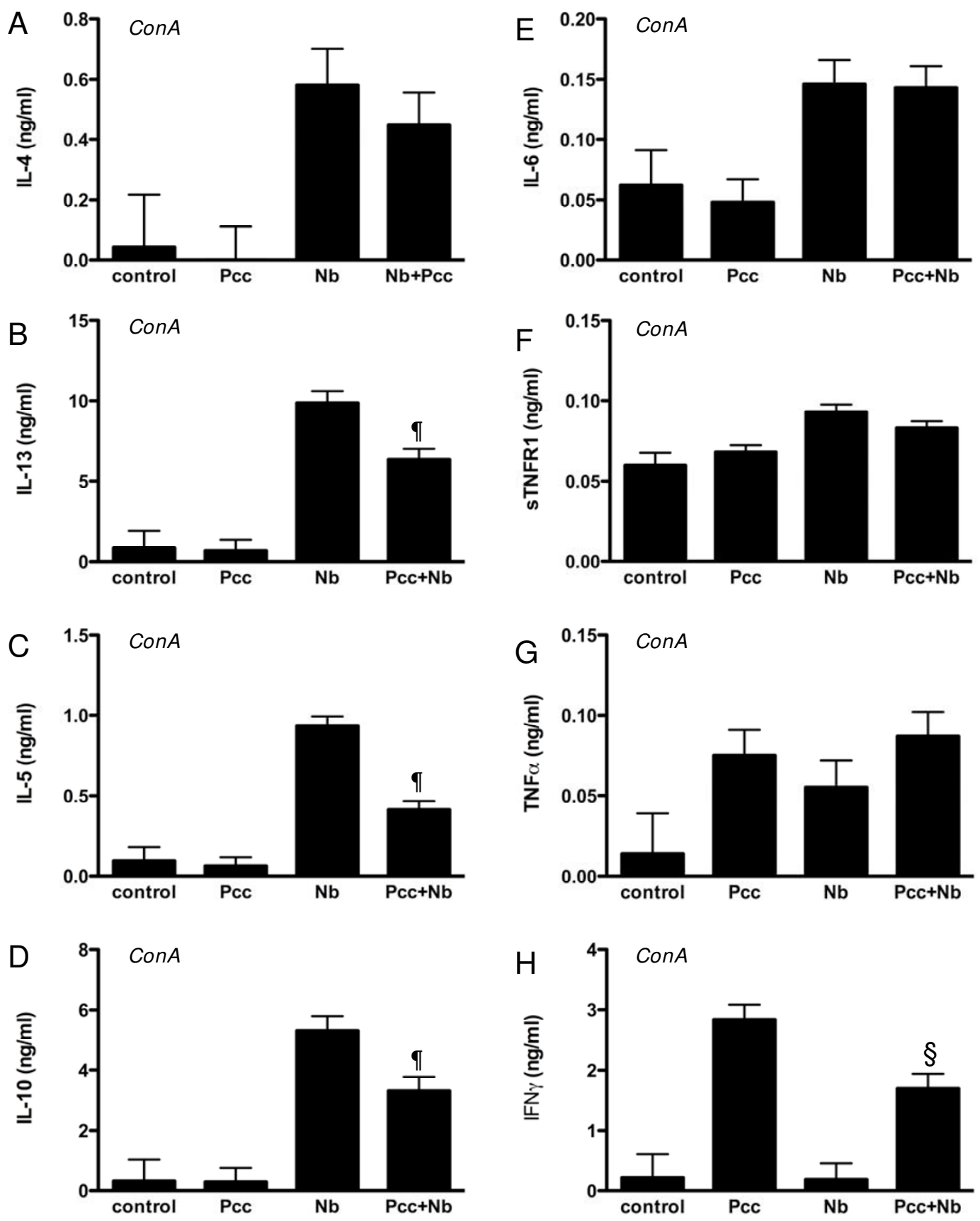

\section{Figure 8}

ConA-induced cytokine release in TLN lymphocyte recall assays. Cytokine concentrations in supernatants of ConAstimulated TLN cells harvested at day 7 pi were measured with cytometric bead arrays. Groups did not differ in cytokine production at 3 or 5 days pi, and no antigen-specific responses were detected until 20 days pi. Data on day 7 pi IL-4 (A), IL-I3 (B), IL-5 (C), IL-I 0 (D), IL-6 (E), sTNFR I (F), TNF- $\alpha(G)$, and IFN- $\gamma(H)$ production are shown. In these data, statistically significant down-regulatory effects of co-infection $(\mathrm{Nb}+\mathrm{PcC})$ were found for IL-I $3(P=0.0 \mathrm{II})$, IL-5 $(P=0.000 \mathrm{I})$, IL-I0 $(P=0.007)$, and IFN$\gamma(P=0.006)$, compared to relevant single-infection groups. Bars indicate mean \pm SEM from 3 combined experiments, each with 4-9 mice per group. The symbol $\prod$ indicates significance of the difference between co-infected and $\mathrm{Nb}$ mice, while $\S$ indicates significance of the difference between co-infected and Pcc mice ( $P$ values included above and in Results text). 


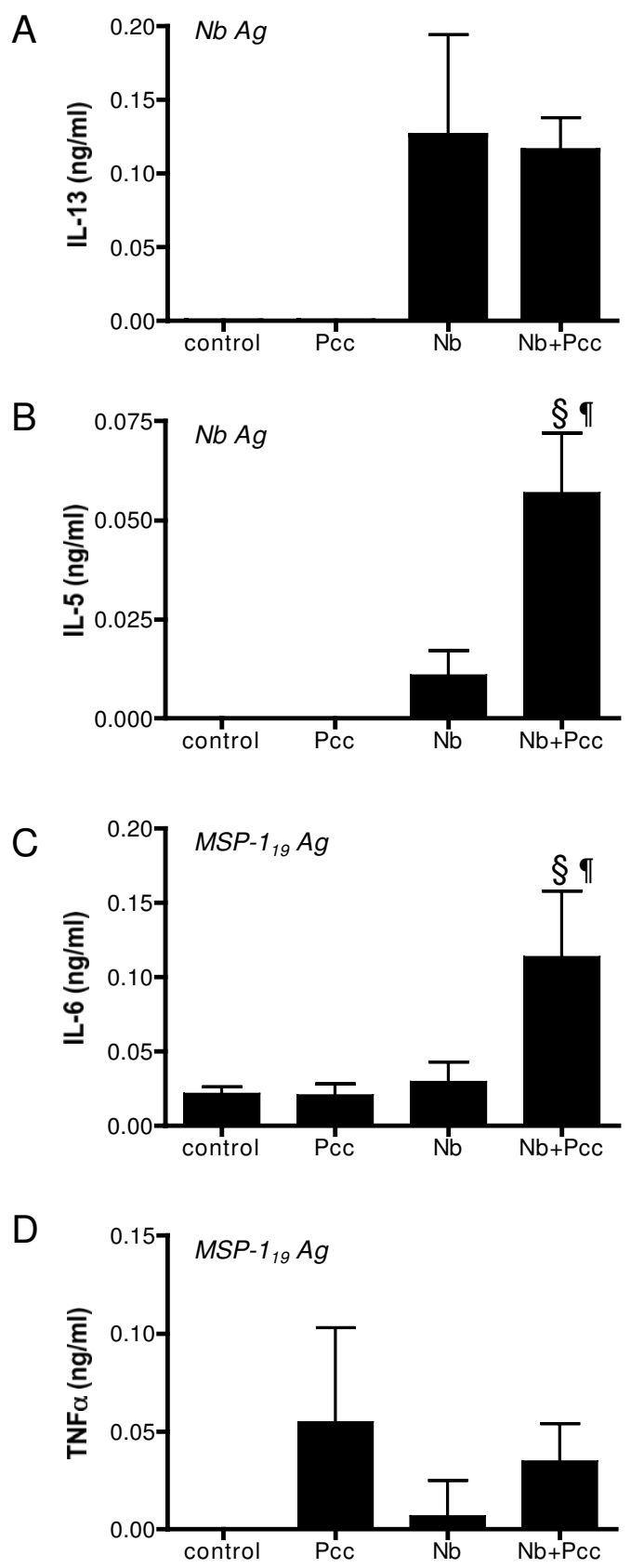

Figure 9

Antigen-specific responses in TLN lymphocyte recall assays. Cytokine concentrations in supernatants of TLN cells that were harvested at day $20 \mathrm{pi}$ and then stimulated with antigen were measured with cytometric bead arrays. $\mathrm{Nb} \mathrm{Ag}$, a crude $\mathrm{Nb}$ adult lysate, and recombinant Pcc clone AS merozoite surface protein, MSP-I 19 , were used as antigens in vitro. Although all cytokines shown in Figure 8 were measured, only IL- I 3 in response to $\mathrm{Nb} A g(\mathrm{~A})$, IL-5 in response to $\mathrm{Nb} A g(\mathrm{~B}), \mathrm{IL}-6$ in response to MSP-I ${ }_{19}(C)$, and TNF- $\alpha$ in response to MSP-I $I_{19}(D)$ were above levels of spontaneous secretion. These figures thus depict antigen-specific cytokine (in $\mathrm{ng} / \mathrm{ml}$ above background). Statistically significant differences among groups included increased NbAg-specific IL-I 3 in all $\mathrm{Nb}$ mice $(P<0.000 \mathrm{I})$, increased $\mathrm{Nb}$ Ag-specific IL-5 in co-infected $(\mathrm{Nb}+\mathrm{Pcc})$ mice compared to both $\mathrm{Nb}(P=0.0025)$ and $P c c$ mice $(P<0.000 \mathrm{I})$, and increased MSP-I 19 -specific IL-6 in Nb+Pcc compared to both $N b(P=$ $0.0163)$ and $P c c$ mice $\left(P=0.01\right.$ I2). Bars indicate mean \pm SEM for 4-8 mice per group. The symbol $\prod$ indicates significance of the difference between co-infected and $\mathrm{Nb}$ mice, while $\S$ indicates significance of the difference between co-infected and $P c c$ mice $(P$ values included above and in Results text). 
microparasite that might reduce Th2 responses to $\mathrm{Nb}$ infection. Mycobacterium bovis BCG co-infection, however, does not significantly impact $N b$-induced IL-4 in the mesenteric lymph nodes [62]; it would be of interest to know whether those lung-dwelling microparasites might have had similar effects to Pcc on Th2 responses, had they been measured in the TLN. Reported effects of $\mathrm{Nb}$ on the course of microparasite infections are likewise mixed: densities of $T$. gondii [60] and M. bovis BCG [62] are unaffected by the presence of the nematode, while C. abortus density increases dramatically [61]. Interestingly, the concurrent presence of influenza virus with migrating $\mathrm{Nb}$ larvae in the lung exacerbates the severity of lung disease compared to mice with influenza alone [40]. A two-week delay between $N b$ infection and influenza infection, or replacement of $\mathrm{Nb}$ with $H$. polygyrus, eliminates the added pathology, suggesting that the simultaneous presence of larvae and virus in the lungs is required [40]. Such may also be the case for $P c c-N b$ co-infection. The $\mathrm{Nb}$-influenza study did not include immunological measurements, so the role of the immune system in generating the observed pattern is not known. Indeed, this comparison illustrates that many details of anatomical location and parasite life cycles, as well as immunological interactions, must be taken into account to explain the diverse outcomes of helminth-microparasite co-infections [30,46].

Our most novel finding is that malaria infection has the capacity to modulate the host's pulmonary Type 2 response to nematode migration. However, the long-term impact of the altered Type 2 response is not possible to predict, because the function of Type 2 immunity in this setting is not yet fully understood. There are at least three potential outcomes of a helminth-induced Type 2 response in the lung. First, it may contribute to protection against incoming larvae [6]. Second, Type 2 responses are likely to be involved in repairing the damage that is inflicted by migrating parasites. Third, as recent studies have shown $[5,16,18]$, lung migration and the associated Th2 responses have the potential to cause long-term lung pathology. Appropriate repair versus lung malfunction are likely to be flip sides of the same coin. Indeed, although ChaFFs and Arginase- 1 are implicated in tissue repair, they are also associated with fibrosis, an overzealous repair process [19,24,43,63-65] (see also review by Wynn [66]). Predicting the effect of Pcc co-infection on long term $N b$-induced lung disease is further complicated by recent data that suggest both Arginase- 1 and RELM $\alpha$ can negatively regulate Th2-mediated pathology [27-29]. By this logic, inhibition of these molecules by malaria coinfection may ultimately exacerbate Th2-mediated lung damage.

However, our data suggest that the effect of malaria on ChaFF expression is not direct but rather via reduced Th2 cytokines. The effect of $P c c$ on $\mathrm{Nb}$-induced ChaFFs was not apparent until 7 days pi, when the extent of the increase in ChaFF expression was inhibited by co-infection. This was correlated with differences in cytokine production in lymphocyte recall assays, suggesting that changes in ChaFF expression were driven by changes in the T lymphocyte populations after the onset of the adaptive Th2 immune response (around 5 days pi, as shown in $\mathrm{Nb}$ infected IL-4 reporter mice [9]). A role for adaptive immunity is further supported by work showing that SCID mice are not able to sustain AAM $\phi$ responses in the lung following $N b$ infection [11], and a demonstrated requirement for T cells to sustain the AAM $\phi$ response in a mouse peritoneal infection model [24]. Remarkably, in SCID mice, in the absence of T cells and AAM $\phi$, the $N b$-induced cellular infiltrate does not resolve [11]. The capacity of malaria to inhibit the transition to a full Th2 response by 7 days pi may likewise be detrimental to full resolution of the inflammatory response, a step necessary for appropriate tissue repair $[67,68]$. By day 20 pi, however, the residual Th2 responses in co-infected mice were as high as, or even higher than, in $\mathrm{Nb}$-only mice. In support of this, day 20 antigen-specific IL-5 responses were particularly high in co-infected animals. Thus Pcc infection may protect against airway hyper-responsiveness through a reduction in peak Th2 activation, or else exacerbate it due to sustained Th2 activity. Transient passage of $\mathrm{Nb}$ larvae through the lung inflicts lasting damage $[16,18]$. Whether transient impairment of pulmonary Th2 responses by malaria co-infection also has lasting effects needs to be investigated experimentally.

A perhaps surprising finding in our study was the apparent absence of classical macrophage activation in the lung despite the clear presence of malaria parasites: we did not detect iNOS, IL-12p40 nor elevated TNF- $\alpha$ mRNA in lung tissue of Pcc-only or co-infected mice at any time point. One could argue that malaria parasites stay in the lung microvasculature and do not cross into tissue. However, this is unlikely to be the case, given the extensive lung damage due to $\mathrm{Nb}$ in co-infected mice, as well as evidence that malaria merozoites can be found dispersed in the lung [34]. Furthermore, IFN- $\gamma$ mRNA was detectable in the lung of all Pcc mice regardless of co-infection, suggesting that lymphocytes were activated, perhaps by innate activation of NK or $\gamma \delta$ T cells. The most likely explanation for the failure to detect classical macrophage activation may be that lung macrophages, which are exposed daily to inhaled microbes, have a remarkably high threshold for activation even in the presence of IFN- $\gamma$ and microbial stimuli [69].

As with any laboratory model, it is important to acknowledge the potential disconnection between natural coinfections and the experimental systems and designs used 
here, including the relative timing of the two infections, doses at which they were administered, and the fact that we have only studied primary and self-resolving (rather than secondary and/or chronic) infections. Permutation of any of these parameters is likely to quantitatively, if not qualitatively, alter outcomes. For example, repair processes might readily keep pace with lung damage when the rate of exposure to nematode larvae is low, unlike in most experimental models. We used a relatively low dose of L3 larvae (200 per mouse while others use $~ 500[16,18]$ or as many as 750-1000 [60-62]) but still exceeded natural exposure levels. Furthermore, larval helminths and malaria parasites are unlikely to arrive in the lung within a few days of each other in nature, and it may be that preexisting malaria would have had a different effect on pulmonary Type 2 responses to $\mathrm{Nb}$ migration, particularly if malaria parasites do not remain long in the lung. Indeed, the most likely natural exposure scenario may be chronic malaria infection into which helminth larvae are "trickled" [32], but experimental studies that mimic this scenario have yet to be carried out. Nonetheless, lung dysfunction is seen as a consequence of helminth migration $[4,5]$ and both acute and persistent malaria infection [38] in people, so high-dose experimental $\mathrm{Nb}$ studies in which long-term lung pathology can be observed $[16,18]$, combined with simultaneous malaria exposure, may provide useful models for disease states in people.

\section{Conclusion}

With the experiments reported here, we have established an acute laboratory model of helminth-malaria co-infection that will be suitable for future work exploring the details of how Type 1 inducing co-infections affect longterm, Type 2-mediated repair of the damage caused by migrating nematodes. Recently developed models of malaria-induced lung damage (e.g., [37]) might be analysed in animals co-infected with $\mathrm{Nb}$. Corroborative studies in human populations may also be feasible. Like migratory helminthiases [3], severe falciparum malaria is associated with detectable lung injury, as measured by spirometry and clinical symptoms [38]. A study like Brooker et al's analysis of whether the anaemia of hookworm and malaria are additive during co-infection [32] that used spirometry to assess the pulmonary health of malaria-infected, A. lumbricoides- or hookworm-infected, and co-infected people could assess whether co-infection exacerbates damage. Given the huge number of people with such co-infections, it is possible that clinical studies of malaria lung injury may gain insight from considering the presence, however transient, of helminths in the lung.

\section{Methods}

Mice, parasites, experimental design, and monitoring

Specific pathogen free, 8-10 week old female BALB/c mice (Harlan, UK) were maintained in individually ventilated cages on diet 41b ad lib. Nippostrongylus brasiliensis $(\mathrm{Nb})$ was maintained by serial passage through Sprague-Dawley rats, as described previously [70]. Cryopreserved Plasmodium chabaudi chabaudi $(P c c)$ parasites of clone AS were passaged through two generations of donor BALB/c mice and inoculated into experimental mice as described previously [50]. The four co-infection experiments used a factorial design, with uninfected controls, $P c c$-infected, $\mathrm{Nb}$ infected, and co-infected mice. On day 0, $200 \mathrm{Nb}$ L3 larvae and/or $10^{5} \mathrm{Pcc}$-infected RBCs were injected subcutaneously and intraperitoneally, respectively. PBS and naïve mouse RBCs served as sham injections for $\mathrm{Nb}$ and $P c c$, respectively; uninfected control animals received both sham injections. RBC density, body mass, and malaria parasites were then monitored daily, as described previously [50]. Briefly, RBC densities were measured by flow cytometry (Beckman Coulter), body mass was recorded to the nearest $0.1 \mathrm{~g}$, and the proportion of RBCs parasitized was counted in Giemsa-stained thin blood films (at $1000 \times$ magnification). Mice were then culled 3, 5, 7, or 20 days pi (4-9 mice per infection type per timepoint). $\mathrm{Nb}$ parasite burden was assessed in the gastrointestinal tract of culled mice. Intestines were placed in PBS, slit lengthwise and the contents rinsed into muslin-lined funnels set over tubes containing PBS warmed to $37^{\circ} \mathrm{C}$. Nematodes were left to filter through for $>2$ hours and counted via microscopy (at 40×). To elucidate the dynamics of $\mathrm{Nb}$ induced alternative activation in the lung, a separate experiment was conducted for $\mathrm{Nb}$ only, with mice culled $3,5,7,15,20$ or 26 days pi ( $4 \mathrm{Nb}$-infected mice per time point). All experiments were carried out in accordance with the animals (Scientific Procedures) Act 1986, and were approved by the UK Home Office inspectorate and institutional review committee.

\section{Lung lavage and tissue sampling}

Following terminal anaesthesia, tracheas were cannulated and lungs lavaged with $1 \mathrm{~mL}$ PBS. Cannulae were prepared from fine bore polythene tubing (Portex) and a 23 $\mathrm{G}$ needle. Following lavage, the left lung lobe was tied off, cut at the bronchus, and placed in RNAlater (Ambion) for mRNA extraction, while the right lobe was perfused in $4 \%$ formaldehyde and embedded in paraffin for immunohistochemistry. BAL cell concentrations were determined using a Scharf Instruments Casy Counter. BALF was centrifuged at $1,200 \mathrm{~g}$ for $5 \mathrm{mins}$ and stored at $-20^{\circ} \mathrm{C}$ for protein analysis by Western blot.

\section{Immunohistochemistry}

Expression of RELM $\alpha$ and Ym1 in lung sections was assessed by indirect immunoperoxidase techniques. Briefly, the paraffin embedded tissue sections were deparaffinised and rehydrated. After high temperature antigen unmasking (Vector Laboratories, UK), endogenous peroxidase was quenched with aqueous $2 \% \mathrm{H}_{2} \mathrm{O}_{2}$ (Sigma 
Aldrich, UK) for 15 minutes. Slides were then incubated 2 $\mathrm{h}$ with primary antibodies: rabbit anti-RELM $\alpha(0.25 \mu \mathrm{g} /$ $\mathrm{mL}$; Peprotech) or rabbit anti-Ym1 (1/100; StemCell Technologies) in antibody diluent (Dako Cytomation, Denmark) at RT, followed by the secondary antibody (goat anti-rabbit biotin, $1 \mathrm{mg} / \mathrm{mL}$, Dako Cytomation, Denmark). Peroxidase-labelled $\mathrm{ABC}$ reagent and $\mathrm{DAB}$ substrate (Vector Laboratories, UK) were used for signal visualisation. Finally, the sections were counterstained with haematoxylin. RELM $\alpha$ and Ym1 staining intensities were scored by two researchers, blinded to experimental groupings, using a modification of a previously-published lung inflammation scoring system [71]. For each mouse, staining was assessed at $200 \times$ magnification for 10 fields. Each field included correctly inflated lung tissue and a complete transection of at least one bronchiole, blood vessel and alveolar airway. Cytoplasmic staining strength was scored in bronchial epithelial cells, infiltrating cells and alveolar macrophages on a scale of 1-4 (1 = no staining, 2 = weak, 3 = moderate, and $4=$ strong staining, using a reference section of the same positive control sample (lung of an $\mathrm{Nb}$-infected mouse at 7 days pi). The percentage of positive cells in each of these compartments was also scored on a scale of $1-4(1=$ none, $2<30 \%, 3=30$ $60 \%, 4>60 \%$ positive cells). Average cytoplasmic and cell positivity scores across the 10 fields were calculated. Finally, the overall staining score for each mouse was calculated by multiplying the average stain strength by average $\%$ positive cells. Control sections incubated with antibody diluent followed by secondary antibody only, or with normal rabbit serum alone, did not show any staining. Mouse lung pathology experts confirmed that stained cell types were correctly identified. Photomicrographs of representative sections were captured on a Zeiss Axioskop microscope with QCapture Pro Software.

\section{RNA isolation and real-time RT-PCR}

RNA isolation from lung tissue was carried out using TRIzol (Invitrogen). After DNase treatment $(10 \mathrm{U} / \mathrm{mL}$ DNase1, Ambion), cDNA was synthesised using Moloney murine leukaemia virus reverse transcriptase (Stratagene). For quantification of Ym1, RELM $\alpha$, Arginase 1, iNOS, IL$12 \mathrm{p} 40$, TNF- $\alpha$, IFN- $\gamma$ and IL-13 mRNA, real-time RT-PCR was performed using a LightCycler (Roche Diagnostics) and primers reported previously [63]. For each gene, five serial 1:4 dilutions of CDNA of a positive control sample (for RELM $\alpha$, Ym1 and Arg1, peritoneal macrophages of a mouse implanted with Brugia malayi adult parasites for 3 weeks [72]; for IL-13, spleen of an MHV-68 infected IFN $\gamma$ R-KO mouse [63]; or for iNOS and other Type 1 markers, peritoneal macrophages of a thioglycolateinjected mouse [10]) were used in each reaction. Amplification was quantified and normalised using $\beta$-actin as a housekeeping gene. PCR reactions were carried out in 10 $\mu$ l buffer containing $1 \mu \mathrm{l} \mathrm{cDNA}, 4 \mathrm{mM} \mathrm{MgCl}_{2}, 0.3 \mu \mathrm{M}$ of each primer and the LightCycler-DNA SYBR Green I mix, under the following conditions: $30 \mathrm{~s}$ denaturation at $95^{\circ} \mathrm{C}, 5 \mathrm{~s}$ annealing of primers at $55^{\circ} \mathrm{C}$ or $63^{\circ} \mathrm{C}(\mathrm{Ym} 1)$, and $12 \mathrm{~s}$ elongation at $72^{\circ} \mathrm{C}$, for 50 cycles. SYBR Green fluorescence was monitored after each cycle at $86^{\circ} \mathrm{C}$ $\left(85^{\circ} \mathrm{C}\right.$ for $\left.\mathrm{Ym} 1\right)$.

\section{Real-time PCR to detect malaria in lung tissue}

Real-time PCR for Pcc genomic DNA was carried out on DNA extracted with phenol/chloroform from homogenized lung tissue (stored in Trizol, Invitrogen; $75 \mathrm{mg}$ tissue $/ \mathrm{mL}$ ). PCR was performed on an ABI Prism 7000 (Applied Biosystems), with primers for merozoite surface protein (MSP)-1 of clone AS, as described previously [73].

\section{Western blot for Ym I and RELM}

$20 \mu \mathrm{l}$ BALF was mixed with sample buffer supplemented with denaturing buffer (NuPage, Invitrogen), heat denatured and resolved by SDS-PAGE using 4-12\% gradient Bis-Tris gels (NuPage, Invitrogen) followed by transfer onto nitrocellulose membrane (Bio-Rad). Transfer and loading intensity were assessed with Ponceau Red staining (Sigma). After blocking with 0.05\% Tween 20 in Starting Block (Pierce), membranes were incubated overnight at $4{ }^{\circ} \mathrm{C}$ with polyclonal rabbit anti-Ym 1 [10] $(0.12 \mathrm{ng} / \mathrm{mL})$ or rabbit anti-RELM $\alpha(0.2 \mu \mathrm{g} / \mathrm{mL}$; Peprotech). After incubation with HRP-conjugated goat anti-rabbit IgG (heavy plus light chains; Bio-Rad; 1/2000), signal was detected with chemiluminescence (ECL kit, Amersham Pharmacia Biotech) and exposure to Hyper ECL film (Amersham). Control blots were incubated with secondary antibody only. Band intensity was determined with the FluorChem SP imager system and software (Alpha Innotech, USA) and expressed as percentage relative to a positive control (pooled lung lavages of three $\mathrm{Nb}$-infected mice) on each blot.

\section{Measurement of cytokine and cytokine receptor responses in local lymph nodes}

Thoracic lymph node (TLN) cells were cultured at $5 \times 10^{5}$ cells per well, with $1 \mu \mathrm{g} / \mathrm{mL}$ Concanavalin A (ConA), 10 $\mu \mathrm{g} / \mathrm{mL}$ adult $\mathrm{Nb}$ parasite extract, $1 \mu \mathrm{g} / \mathrm{mL}$ of recombinant Pcc Merozoite Surface Protein MSP- $1_{19}$, or medium alone at $37^{\circ} \mathrm{C}$. After $72 \mathrm{~h}$, supernatants were harvested. Concentrations of IL-4, IFN- $\gamma$, TNF- $\alpha$, IL-5, IL-6, IL-10 and IL-13 were then measured using Cytometric Bead Array Flex Sets (BD Biosciences), with slight modifications from manufacturer's instructions: $50 \mu \mathrm{l}$ samples/standards were incubated with capture beads $(0.5 \mu \mathrm{l}$ per sample per cytokine, plus diluent to $25 \mu \mathrm{l}$ ) in darkness with shaking for $1 \mathrm{~h}$ at RT. Plates were washed, spun at $200 \mathrm{~g}$ for $5 \mathrm{~min}$, and then incubated with $25 \mu \mathrm{l}$ of PE-conjugated anti-cytokine antibodies in darkness for $1 \mathrm{~h}$. After washing and resuspension of beads, data were acquired on a FACSArray with FCAP software (BD Biosciences). Soluble TNF Receptor-1 
(sTNFR1) concentrations were determined by sandwich ELISA, using $2 \mu \mathrm{g} / \mathrm{mL}$ capture antibody (clone MAB425), $200 \mathrm{ng} / \mathrm{mL}$ biotinylated detection antibody (BAF425), and recombinant mouse sTNFR1 as standard (425-R1; all from R\&D Systems). Plates were blocked with 5\% BSA in TBS for $2 \mathrm{~h}$ at RT and washed with TBS $/ 0.05 \%$ Tween (TBST) before $50 \mu \mathrm{l}$ samples were incubated overnight at $4{ }^{\circ} \mathrm{C}$. Plates were washed, incubated with detection reagent for $2 \mathrm{~h}$ at RT, washed again, and then incubated with streptavadin-HRP (Sigma Aldrich) at RT for 20 min. Plates were washed again and developed with TMB SureBlue substrate system (KPL 52-00-03). The reaction was stopped after 30 min with $1 \mathrm{M} \mathrm{HCl}$ and read on a spectrophotometer at $450 \mathrm{~nm}$.

\section{Statistical analysis}

Most data were analysed with SAS System 9.1 mixedmodel analyses of variance (ANOVA) or covariance (ANCOVA) [74] (see exceptions below). To meet the homogeneity-of-variance assumption of such analyses, data were logarithmically transformed. To account for slight differences among experiments in, for example, the magnitude of ConA-stimulated cytokine production, experiment was included as a random factor in all models. All significant effects of infection reported below have therefore remained significant after controlling for effects of experiment, if any. To account for differences among mice in starting body mass or RBC density, day 0 values were included as covariates. Pathology analyses focused on animals that experienced the full 20-day course of infection, and minimum body weight and RBC density were analysed in two time frames: the first week pi, and the entire experiment. In accord with the factorial design of the experiments, $P c c$ and $\mathrm{Nb}$ infection were fit as fixed factors. Wherever the interaction term was significant (indicating a potential effect of co-infection), post-hoc ttests adjusted for multiple comparisons were run. A Tukey-Kramer-corrected $P<0.05$ was used as the cut-off for significance. For relevant subsets of mice, an $\mathrm{Nb}$ fixed factor was used to test whether co-infection altered Pcc parasitaemia, while a Pcc fixed factor tested whether coinfection altered expression of ChaFFs.

Following logarithmic transformation to meet the assumptions of parametric statistical analysis, the ChaFF time courses, IHC scores, and lung Pcc data were analysed with unpaired $t$-tests in Prism 4 (Graph Pad Software, Berkeley, USA), with a two-tailed $P<0.05$ designated as significant. Only two groups were compared per dataset, as specified in the Results section.

\section{Abbreviations}

AAM $\phi$ : (alternatively activated macrophages); BALF: (bronchioalveolar lavage fluid); ChaFFs: (chitinase and Fizz/resistin family members); IHC: (immunohistochem- istry); IL: (interleukin); Nb: (Nippostrongylus brasiliensis); Pcc: (Plasmodium chabaudi chabaudi); pi: (post-infection); RBC: (Red Blood Cell); RELM $\alpha$ : (resistin-like molecule $\alpha$ ); Th: (T helper); TLN: (thoracic lymph node).

\section{Authors' contributions}

MAH conducted RT-PCR analysis of ChaFFs and PCR analysis of $P c c$ genomes, ran Western blots, statistically analysed some of the data, assisted with IHC scoring, and helped to draft the manuscript. KJM led the lung sampling, conducted cytokine RT-PCR reactions, assisted with Western blots, did IHC staining and scoring, and helped to draft the manuscript. Additionally, KJM collected all data for the $\mathrm{Nb}$ timecourse experiment. KJF-C, aided by ALG, set up all co-infection experiments and collected parasitemia, body mass and anaemia data. SM, aided by KJF$\mathrm{C}$, cultured lymph node cells and measured cytokines and cytokine receptors in the supernatants. JEA and ALG conceived of and designed the study, and drafted the manuscript. ALG performed most of the statistical analysis. All authors contributed to scientific discussions of the data, read and approved the final manuscript.

\section{Acknowledgements}

This work was supported by the U.K. Biotechnology and Biological Sciences Research Council (grant BB/C508734/I to JEA and ALG, and David Phillips Fellowship BB/D01977X/I to ALG) and the KNAW/Royal Netherlands Academy of Arts and Science (a Ter Meulen Fund Fellowship to MAH). The assistance of Y. Harcus and R. Maizels (for L3 larvae), K. Filbey, M. Leech, H. McSorley, and T. Sutherland (for lung sampling), S. Johnston (for flow cytometry), and M. Leech and S. Howie (for IHC scoring and photomicroscopy) is gratefully acknowledged. In addition, we thank the animal house staff for husbandry, J. Langhorne for the kind gift of MSP-I ${ }_{19}, A$. Bell and A. Read for Pcc primers, and A. MacDonald and T. Sutherland for insightful comments.

\section{References}

I. Bethony J, Brooker S, Albonico M, Geiger SM, Loukas A, Diemert D, Hotez PJ: Soil-transmitted helminth infections: ascariasis, trichuriasis, and hookworm. Lancet 2006, 367:1521-1532.

2. Hotez PJ, Brooker S, Bethony JM, Bottazzi ME, Loukas A, Xiao S: Hookworm infection. N Engl J Med 2004, 351:799-807.

3. Sarinas PS, Chitkara RK: Ascariasis and hookworm. Semin Respir Infect 1997, I 2: I30-137.

4. Palmer LJ, Celedon JC, Weiss ST, Wang B, Fang Z, Xu X: Ascaris lumbricoides infection is associated with increased risk of childhood asthma and atopy in rural China. Am J Respir Crit Care Med 2002, 165:|489-1493.

5. da Silva ER, Sly PD, de Pereira MU, Pinto LA, Jones MH, Pitrez PM, Stein RT: Intestinal helminth infestation is associated with increased bronchial responsiveness in children. Pediatr Pulmonol 2008, 43:662-665

6. Finkelman FD, Shea-Donohue T, Morris SC, Gildea L, Strait R, Madden KB, Schopf L, Urban JF Jr: Interleukin-4- and interleukin- I3mediated host protection against intestinal nematode parasites. Immunol Rev 2004, 20 I: 139-155.

7. Stadnyk AW, McElroy PJ, Gauldie J, Befus AD: Characterization of Nippostrongylus brasiliensis infection in different strains of mice. J Parasitol 1990, 76:377-382.

8. Min B, Prout M, Hu-Li J, Zhu J, Jankovic D, Morgan ES, Urban JF Jr, Dvorak AM, Finkelman FD, LeGros G, Paul WE: Basophils produce IL-4 and accumulate in tissues after infection with a Th2inducing parasite. J Exp Med 2004, 200:507-517. 
9. Voehringer D, Shinkai K, Locksley RM: Type 2 immunity reflects orchestrated recruitment of cells committed to IL-4 production. Immunity 2004, 20:267-277.

10. Nair MG, Gallagher IJ, Taylor MD, Loke P, Coulson PS, Wilson RA, Maizels RM, Allen JE: Chitinase and Fizz family members are a generalized feature of nematode infection with selective upregulation of $\mathrm{Ym} \mathrm{I}$ and Fizz I by antigen-presenting cells. Infect Immun 2005, 73:385-394.

II. Reece J], Siracusa MC, Scott AL: Innate immune responses to lung-stage helminth infection induce alternatively activated alveolar macrophages. Infect Immun 2006, 74:4970-498I.

12. Gordon S: Alternative activation of macrophages. Nat Rev Immunol 2003, 3:23-35.

13. Loke P, Nair MG, Parkinson J, Guiliano D, Blaxter M, Allen JE: IL-4 dependent alternatively-activated macrophages have a distinctive in vivo gene expression phenotype. BMC Immunol 2002, 3:7.

14. Nair MG, Cochrane DW, Allen JE: Macrophages in chronic type $\mathbf{2}$ inflammation have a novel phenotype characterized by the abundant expression of $\mathrm{Ym} \mathrm{I}$ and Fizzl that can be partly replicated in vitro. Immunol Lett 2003, 85:I73-I80.

I5. Raes G, De Baetselier P, Noel W, Beschin A, Brombacher F, Hassanzadeh GhG: Differential expression of FIZZI and Ym I in alternatively versus classically activated macrophages. J Leukoc Biol 2002, 7 I:597-602.

16. Marsland BJ, Kurrer M, Reissmann R, Harris NL, Kopf M: Nippostrongylus brasiliensis infection leads to the development of emphysema associated with the induction of alternatively activated macrophages. Eur J Immunol 2008, 38:479-488.

17. Pesce J, Kaviratne M, Ramalingam TR, Thompson RW, Urban JF Jr, Cheever AW, Young DA, Collins M, Grusby MJ, Wynn TA: The IL2 I receptor augments Th2 effector function and alternative macrophage activation. J Clin Invest 2006, I I 6:2044-2055.

18. Reece J], Siracusa MC, Southard TL, Brayton CF, Urban JF Jr, Scott AL: Hookworm-Induced Persistent Changes to the Immunological Environment of the Lung. Infect Immun 2008, 76:35 I I-3524.

19. Hesse M, Modolell M, La Flamme AC, Schito M, Fuentes JM, Cheever AW, Pearce EJ, Wynn TA: Differential regulation of nitric oxide synthase- 2 and arginase-I by type I/type 2 cytokines in vivo: granulomatous pathology is shaped by the pattern of Larginine metabolism. J Immunol 200 I, I 67:6533-6544.

20. Witte MB, Barbul A: Arginine physiology and its implication for wound healing. Wound Repair Regen 2003, I I :4 I9-423.

21. Anthony RM, Urban JF, Alem F, Hamed HA, Rozo CT, Boucher JL, Van Rooijen N, Gause WC: Memory $\mathbf{T}(\mathbf{H}) 2$ cells induce alternatively activated macrophages to mediate protection against nematode parasites. Nat Med 2006, 1 2:955-960.

22. Eming SA, Werner S, Bugnon P, Wickenhauser C, Siewe L, Utermohlen O, Davidson JM, Krieg T, Roers A: Accelerated wound closure in mice deficient for interleukin-10. American Journal of Pathology 2007, I 70: $188-202$

23. Hung SL, Chang AC, Kato I, Chang NCA: Transient expression of Ym I, a heparin-binding lectin, during developmental hematopoiesis and inflammation. J Leukoc Biol 2002, 72:72-82.

24. Loke P, Gallagher I, Nair MG, Zang X, Brombacher F, Mohrs M, Allison JP, Allen JE: Alternative activation is an innate response to injury that requires CD4+ $T$ cells to be sustained during chronic infection. J Immunol 2007, I 79:3926-3936.

25. Chang NCA, Hung SI, Hwa KY, Kato I, Chen JE, Liu CH, Chang AC: A macrophage protein, $\mathrm{YmI}$, transiently expressed during inflammation is a novel mammalian lectin. Journal of Biological Chemistry 200I, 276: I7497-17506.

26. Liu TJ, Dhanasekaran SM, Jin H, Hu B, Tomlins SA, Chinnaiyan AM, Phan $\mathrm{SH}$ : FIZZI stimulation of myofibroblast differentiation. American Journal of Pathology 2004, 164:1315-1326.

27. Nair MG, Du Y, Perrigoue JG, Zaph C, Taylor Jj, Goldschmidt M, Swain GP, Yancopoulos GD, Valenzuela DM, Murphy A, et al:: Alternatively activated macrophage-derived RELM-\{alpha\} is a negative regulator of type 2 inflammation in the lung. $J E x p$ Med 2009, 206:937-952.

28. Pesce JT, Ramalingam TR, Mentink-Kane MM, Wilson MS, El Kasmi KC, Smith AM, Thompson RW, Cheever AW, Murray PJ, Wynn TA: Arginase- I-expressing macrophages suppress Th2 cytokinedriven inflammation and fibrosis. PLoS Pathog 2009, 5:e I 00037I

29. Pesce JT, Ramalingam TR, Wilson MS, Mentink-Kane MM, Thompson RW, Cheever AW, Urban JF Jr, Wynn TA: Retnla (relmalphal fizz I) suppresses helminth-induced Th2-type immunity. PLoS Pathog 2009, 5:e l000393.

30. Hartgers FC, Yazdanbakhsh M: Co-infection of helminths and malaria: modulation of the immune responses to malaria. Parasite Immunol 2006, 28:497-506.

31. Mwangi TW, Bethony JM, Brooker S: Malaria and helminth interactions in humans: an epidemiological viewpoint. Ann Trop Med Parasitol 2006, 1 00:55I-570.

32. Brooker S, Akhwale W, Pullan R, Estambale B, Clarke SE, Snow RW Hotez PJ: Epidemiology of plasmodium-helminth co-infection in Africa: populations at risk, potential impact on anemia, and prospects for combining control. Am J Trop Med Hyg 2007. 77:88-98.

33. Li C, Seixas E, Langhorne J: Rodent malarias: the mouse as a model for understanding immune responses and pathology induced by the erythrocytic stages of the parasite. Med Microbiol Immunol 2001, 189: I 15-126.

34. Coquelin F, Boulard Y, Mora-Silvera E, Richard F, Chabaud AG, Landau I: Final stage of maturation of the erythrocytic schizonts of rodent Plasmodium in the lungs. C R Acad Sci III 1999, 322:55-62.

35. Baer K, Klotz C, Kappe SH, Schnieder T, Frevert U: Release of hepatic Plasmodium yoelii merozoites into the pulmonary microvasculature. PLoS Pathog 2007, 3: I7I.

36. Lovegrove FE, Pena-Castillo L, Mohammad N, Liles WC, Hughes TR, Kain KC: Simultaneous host and parasite expression profiling identifies tissue-specific transcriptional programs associated with susceptibility or resistance to experimental cerebral malaria. BMC genomics 2006, 7:295.

37. Lovegrove FE, Gharib SA, Pena-Castillo L, Patel SN, Ruzinski JT, Hughes TR, Liles WC, Kain KC: Parasite Burden and CD36Mediated Sequestration Are Determinants of Acute Lung Injury in an Experimental Malaria Model. PLoS Pathog 2008, 4:el000068

38. Maguire GP, Handojo T, Pain MC, Kenangalem E, Price RN, Tjitra E, Anstey NM: Lung injury in uncomplicated and severe falciparum malaria: a longitudinal study in papua, Indonesia. Infect Dis 2005, I 92:1966-1974.

39. Furze RC, Hussell T, Selkirk ME: Amelioration of influenzainduced pathology in mice by coinfection with Trichinella spiralis. Infect Immun 2006, 74: I924-I 932.

40. Wescott RB, Todd AC: Interaction of Nippostrongylus brasiliensis and influenza virus in mice. I. Influence of the nematode on the virus. J Parasitol 1966, 52:242-247.

4I. Mercer JG, Mitchell PI, Moar KM, Bissett A, Geissler S, Bruce K, Chappell $\mathrm{LH}$ : Anorexia in rats infected with the nematode, Nippostrongylus brasiliensis: experimental manipulations. Parasitology 2000, I 20(Pt 6):64I-647.

42. Holcomb IN, Kabakoff RC, Chan B, Baker TW, Gurney A, Henzel W, Nelson C, Lowman HB, Wright BD, Skelton NJ, et al.: FIZZI, a novel cysteine-rich secreted protein associated with pulmonary inflammation, defines a new gene family. Embo J 2000, 1 9:4046-4055.

43. Mora AL, Torres-Gonzalez E, Rojas M, Corredor C, Ritzenthaler J, Xu J, Roman J, Brigham K, Stecenko A: Activation of alveolar macrophages via the alternative pathway in herpesvirus-induced lung fibrosis. Am J Respir Cell Mol Biol 2006, 35:466-473.

44. Siracusa MC, Reece JJ, Urban JF Jr, Scott AL: Dynamics of lung macrophage activation in response to helminth infection. J Leukoc Biol 2008, 84:|422-|433.

45. Su Z, Stevenson MM: Central role of endogenous gamma interferon in protective immunity against blood-stage Plasmodium chabaudi AS infection. Infect Immun 2000, 68:4399-4406.

46. Page KR, Scott AL, Manabe YC: The expanding realm of heterologous immunity: friend or foe? Cell Microbiol 2006, 8: I85-196.

47. Mohrs K, Harris DP, Lund FE, Mohrs M: Systemic dissemination and persistence of Th2 and type 2 cells in response to infection with a strictly enteric nematode parasite. J Immunol 2005 , | 75:5306-53|3.

48. Lamb TJ, Graham AL, Le Goff L, Allen JE: Co-infected C57BL/6 mice mount appropriately polarized and compartmentalized cytokine responses to Litomosoides sigmodontis and Leishmania major but disease progression is altered. Parasite Immunol 2005, 27:3 I7-324. 
49. Mackinnon MJ, Read AF: Genetic relationships between parasite virulence and transmission in the rodent malaria Plasmodium chabaudi. Evolution Int J Org Evol 1999, 53:689-703.

50. Graham AL, Lamb TJ, Read AF, Allen JE: Malaria-filaria coinfection in mice makes malarial disease more severe unless filarial infection achieves patency. J Infect Dis 2005, I 9 I:4 I 0-42 I.

51. Helmby H, Kullberg M, Troye-Blomberg M: Altered immune responses in mice with concomitant Schistosoma manson and Plasmodium chabaudi infections. Infect Immun 1998 66:5167-5I74.

52. Legesse M, Erko B, Balcha F: Increased parasitaemia and delayed parasite clearance in Schistosoma mansoni and Plasmodium berghei co-infected mice. Acta Trop 2004, 9 I: |6 I-I66.

53. Noland GS, Graczyk T, Fried B, Fitzgerald EJ, Kumar N: Exacerbation of Plasmodium yoelii malaria in Echinostoma capron infected mice and abatement through anthelmintic treatment. J Parasitol 2005, 9 I:944-948.

54. Su Z, Segura M, Morgan K, Loredo-Osti JC, Stevenson MM: Impair ment of protective immunity to blood-stage malaria by concurrent nematode infection. Infect Immun 2005, 73:353I-3539.

55. Helmby $\mathrm{H}$ : Gastrointestinal nematode infection exacerbates malaria-induced liver pathology. J Immunol 2009, | 82:5663-567|.

56. Stevenson MM, Riley E: Innate immunity to malaria. Nat Rev Immunol 2004, 4: I69-I80.

57. Lwin M, Last C, Targett GAT, Doenhoff MI: Infection of mice concurrently with Schistosoma mansoni and rodent malarias: Contrasting effects of patent S. mansoni infections on Plasmodium chabaudi, $\boldsymbol{P}$. yoelii and $\boldsymbol{P}$. berghei. Ann Trop Med Parasito 1982, 76:265-273

58. Graham AL: Ecological rules governing helminth-microparasite co-infection. Proc Natl Acad Sci USA 2008, I 05:566-570.

59. Cox FEG: Major models in malaria research: rodent. In Malaria: Principles and Practice of Malariology Edited by: Wernsdorfe WH, McGregor I. Edinburgh: Churchill Livingstone; I 988:I503-I543.

60. Liesenfeld O, Dunay IR, Erb KJ: Infection with Toxoplasma gondii reduces established and developing Th2 responses induced by Nippostrongylus brasiliensis infection. Infect Immun 2004, 72:3812-3822

6I. Buendia A, Fallon PG, Del Rio L, Ortega N, Caro MR, Gallego MC Salinas J: Previous infection with the nematode Nippostrongylus brasiliensis alters the immune specific response against Chlamydophila abortus infection. Microb Pathog 2002, 33:7-I5.

62. Erb KJ, Trujillo C, Fugate M, Moll H: Infection with the helminth Nippostrongylus brasiliensis does not interfere with efficient elimination of Mycobacterium bovis BCG from the lungs of mice. Clin Diagn Lab Immunol 2002, 9:727-730.

63. Gangadharan B, Hoeve MA, Allen JE, Ebrahimi B, Rhind SM, Dutia BM Nash AA: Murine \{gamma\}herpesvirus-induced fibrosis is associated with the development of alternatively activated macrophages. I Leukoc Biol 2008, 84:50-58.

64. Liu T, Jin H, Ullenbruch M, Hu B, Hashimoto N, Moore B, McKenzie A, Lukacs NW, Phan SH: Regulation of found in inflammatory zone I expression in bleomycin-induced lung fibrosis: role of IL-4/IL-I 3 and mediation via STAT-6. J Immunol 2004, | 73:3425-343 |

65. Sandler NG, Mentink-Kane MM, Cheever AW, Wynn TA: Global gene expression profiles during acute pathogen-induced pulmonary inflammation reveal divergent roles for ThI and Th2 responses in tissue repair. J Immunol 2003, I 7 I:3655-3667.

66. Wynn TA: Fibrotic disease and the $\mathbf{T}(\mathbf{H}) I / T(H) 2$ paradigm Nat Rev Immunol 2004, 4:583-594.

67. Ashcroft GS, Mills SJ, Lei K, Gibbons L, Jeong MJ, Taniguchi M, Burow M, Horan MA, Wahl SM, Nakayama T: Estrogen modulates cutaneous wound healing by downregulating macrophage migration inhibitory factor. J Clin Invest 2003, I I I: | 309- I 3 I8.

68. Eming SA, Krieg T, Davidson JM: Inflammation in wound repair: molecular and cellular mechanisms. J Invest Dermatol 2007 1 27:5 | 4-525.

69. Lambrecht BN: Alveolar macrophage in the driver's seat. Immunity 2006, 24:366-368.

70. Lawrence RA, Gray CA, Osborne J, Maizels RM: Nippostrongylus brasiliensis: cytokine responses and nematode expulsion in normal and IL-4-deficient mice. Exp Parasitol I 996, 84:65-73.

7I. Leech MD, Benson RA, De Vries A, Fitch PM, Howie SE: Resolution of Der pl-induced allergic airway inflammation is dependent on CD4+CD25+Foxp3+ regulatory cells. I Immunol 2007, 1 79:7050-7058

72. Mylonas KJ, Nair MG, Prieto-Lafuente L, Paape D, Allen JE: Alternatively activated macrophages elicited by helminth infection can be reprogrammed to enable microbial killing. J Immunol 2009, I 82:3084-3094.

73. Bell AS, de Roode JC, Sim D, Read AF: Within-host competition in genetically diverse malaria infections: parasite virulence and competitive success. Evolution 2006, 60: |358-|37|.

74. Littell RC, Milliken GA, Stroup WW, Wolfinger RD: SAS System for Mixed Models Cary, North Carolina: SAS Institute, Inc; 1996.
Publish with Bio Med Central and every scientist can read your work free of charge

"BioMed Central will be the most significant development for disseminating the results of biomedical research in our lifetime. "

Sir Paul Nurse, Cancer Research UK

Your research papers will be:

- available free of charge to the entire biomedical community

- peer reviewed and published immediately upon acceptance

- cited in PubMed and archived on PubMed Central

- yours - you keep the copyright

Submit your manuscript here:

http://www.biomedcentral.com/info/publishing_adv.asp
BioMedcentral 